\title{
NYX-2925 Is a Novel N-Methyl-D-Aspartate Receptor Modulator that Induces Rapid and Long-Lasting Analgesia in Rat Models of Neuropathic Pain
}

\author{
Nayereh Ghoreishi-Haack, Jessica M. Priebe, Jacqueline D. Aguado, Elizabeth M. Colechio, \\ Jeffrey S. Burgdorf, M. Scott Bowers, Cassia N. Cearley, M. Amin Khan, \\ and Joseph R. Moskal \\ Aptinyx, Inc., Evanston, Illinois (N.G.-H., J.M.P., J.D.A., E.M.C., J.S.B., M.S.B., C.N.C., M.A.K., J.R.M.) and Falk Center for \\ Molecular Therapeutics, Department of Biomedical Engineering, Northwestern University, Evanston, Illinois (J.S.B., M.S.B., \\ J.R.M.)
}

Received April 4, 2018; accepted July 3, 2018

\begin{abstract}
NYX-2925 [(2S,3R)-3-hydroxy-2-((R)-5-isobutyryl-1-oxo-2,5diazaspiro[3.4]octan-2-yl)butanamide] is a novel $N$-methyl-Daspartate (NMDA) receptor modulator that is currently being investigated in phase 2 clinical studies for the treatment of painful diabetic peripheral neuropathy and fibromyalgia. Previous studies demonstrated that NYX-2925 is a member of a novel class of NMDA receptor-specific modulators that affect synaptic plasticity processes associated with learning and memory. Studies here examined NYX-2925 administration in rat peripheral chronic constriction nerve injury $(\mathrm{CCl})$ and streptozotocin-induced diabetic mechanical hypersensitivity. Additionally, NYX-2925 was examined in formalin-induced persistent pain model and the tail flick test of acute nociception. Oral administration of NYX-2925 resulted in rapid and long-lasting analgesia in both of the neuropathic pain models
\end{abstract}

and formalin-induced persistent pain, but was ineffective in the tail flick model. The analgesic effects of NYX-2925 were blocked by the systemic administration of NMDA receptor antagonist 3-(2-carboxypiperazin-4-yl)propyl-1-phosphonic acid. Microinjection of NYX-2925 into the medial prefrontal cortex of $\mathrm{CCl}$ rats resulted in analgesic effects similar to those observed following systemic administration, whereas intrathecal administration of NYX-2925 was ineffective. In $\mathrm{CCl}$ animals, NYX-2925 administration reversed deficits seen in a rat model of rough-and-tumble play. Thus, it appears that NYX-2925 may have therapeutic potential for the treatment of neuropathic pain, and the data presented here support the idea that NYX-2925 may act centrally to ameliorate pain and modulate negative affective states associated with chronic neuropathic pain.

\section{Introduction}

Neuropathic pain is a chronic, debilitating condition arising from insults to the central and peripheral nerves (Gilron et al., 2015). Although there are multiple compounds marketed for the treatment of neuropathic pain, there is still a high unmet medical need. Only one-third of neuropathic pain patients achieve a $50 \%$ pain reduction, and nearly all continue to experience residual pain (Gilron and Dickenson, 2014; Hauser et al., 2014; Finnerup et al., 2015). Moreover, the impaired cognitive and emotional states that are often comorbid with chronic pain remain largely unaddressed with current

Portions of this work was previously presented: 2016: American Pain Society, Austin TX; International Association for the Study of Pain, Yokohama, JP; Society for Neuroscience, San Diego, CA 2017: American Pain Society Pittsburgh, PA; Society for Neuroscience, Washington, DC 2018: American Pain Society, Anaheim, CA

All studies performed for this manuscript were funded by Aptinyx, Inc.

https://doi.org/10.1124/jpet.118.249409. pharmacotherapies. As such, there is a growing need for new therapeutics for the treatment of neuropathic pain.

$N$-methyl-D-aspartate (NMDA) receptors (NMDARs) belong to a family of ligand-gated ionotropic glutamate receptors that are found predominantly in the central nervous system (Cull-Candy et al., 2001; Traynelis et al., 2010). NMDARs are critical for learning and memory (Barker and Warburton, 2008; Burgdorf et al., 2015b), and there is increasing evidence implicating the inappropriate modulation of NMDARs in the etiology of neuropathic pain, including its affective and cognitive components (Apkarian et al., 2013; Bushnell et al., 2013). Specifically, both the chronic and emotional components of neuropathic pain are increasingly understood to rely on changes in NMDAR-dependent plasticity within corticolimbic circuitry, including the medial prefrontal cortex (mPFC) (Apkarian et al., 2013; Bushnell et al., 2013; Kelly and Martina, 2018). Because NMDARs play a crucial role in neuropathic pain, as well as in emotional and cognitive processes, targeting these receptors could help fulfill

ABBREVIATIONS: $\mathrm{CCl}$, chronic constriction injury; CID, compound identification; CMC, carboxymethylcellulose sodium salt; CPP, 3-(2carboxypiperazin-4-yl)propyl-1-phosphonic acid; D, day; DCS, D-cycloserine; mPFC, medial prefrontal cortex; NMDA, N-methyl-D-aspartate; NMDAR, N-methyl-D-aspartate receptor; NYX-2925, (2S,3R)-3-hydroxy-2-((R)-5-isobutyryl-1-oxo-2,5-diazaspiro[3.4]octan-2-yl)butanamide; PO, per os (by mouth); PWL, paw withdrawal latency; PWT, paw withdrawal threshold; STZ, streptozotocin; T, trial; USV, ultrasonic vocalization. 
the existing unmet medical need. Accordingly, several NMDAR-targeted compounds have been studied for the treatment of neuropathic pain. These include the NMDAR antagonist ketamine as well as the NMDAR glycine-site partial agonist D-cycloserine (Coderre and Melzack, 1992; Millan and Seguin, 1994; Seguin and Millan, 1994; Singh et al., 1996). However, results from neuropathic pain clinical studies completed with NMDAR-targeted compounds have been mixed. Ketamine, while showing efficacy, can cause psychotomimetic, sedative, and ataxic side effects, which limits its therapeutic utility (Backonja et al., 1994; Niesters et al., 2014). D-Cycloserine (DCS), although promising, only shows weak-to-moderate effects in studies conducted to date (Holla et al., 2015; Schnitzer et al., 2016). Thus, there is a need for novel NMDAR-targeted therapeutics that operate through alternative mechanisms of modulating the NMDAR.

Recent studies have shown that NYX-2925 [(2S,3R)-3hydroxy-2-((R)-5-isobutyryl-1-oxo-2,5-diazaspiro[3.4]octan-2yl)butanamide], a novel NMDAR-specific modulator, facilitates synaptic plasticity, enhances learning and memory, and has antidepressant-like effects in rats with no effect on locomotor behavior (Khan et al., 2018). NYX-2925 also has a large therapeutic index $(>1000)$ (Khan et al., 2018). This compound interacts with the NMDAR in a different way than other NMDAR-targeted compounds tested to date in that it acts acutely to facilitate NMDAR-dependent plasticity via direct activation of NMDAR and exerts long-lasting effects by enhancing both metaplasticity and structural plasticity (Khan et al., 2018). The goal of the studies reported here was to evaluate the potential therapeutic effect of NYX-2925 in the rat chronic constriction injury (CCI) and diabetes-induced models of neuropathic pain.

\section{Material and Methods}

Drugs. NYX-2925 was synthesized at Sai Life Sciences (Maharashtra, India). All other reagents were obtained in the highest purity available from standard suppliers: gabapentin (CID: 6453919; Spectrum Chemical, New Brunswick, NJ), buprenorphine HCl (CID: 644073; Reckitt Benckiser Pharmaceuticals, Inc., Richmond, VA), formalin (CID: 712; Sigma-Aldrich, St. Louis, MO), 3-(2-carboxypiperazin-4-yl)propyl-1phosphonic acid (CPP; Sigma-Aldrich), streptozotocin (STZ; CID: 29327; Sigma-Aldrich), and carboxymethylcellulose sodium salt (CMC; Sigma-Aldrich). Isoflurane (Novaplus, Irving, TX) was provided by the Center for Comparative Medicine at Northwestern University (Evanston, IL).

Oral Administration. In acute or repeat subtherapeutic dosing studies, vehicle $(0.5 \% \mathrm{CMC}$ in MilliQ water [Millipore, Burlington, MA]), NYX-2925 (0.1-100 mg/kg), or gabapentin (150 mg/kg in sterile water) was administered by oral gavage. For the repeat therapeutic dosing study, conducted by PsychoGenics (Paramus, NJ), gabapentin was dosed at $100 \mathrm{mg} / \mathrm{kg}$ (in sterile water). Both of these gabapentin concentrations show robust and roughly equivalent analgesic effects with no observable adverse events. In the CCI studies, dosing occurred 2-3 weeks post surgery. In the STZ-induced diabetic neuropathy study, dosing occurred 4-5 weeks post initial STZ injection.

Medial Prefrontal Cortex Microinjection. NYX-2925 (0.01, 0.1, or $1 \mu \mathrm{g} / 0.5 \mu \mathrm{l}$ saline) or $0.5 \mu \mathrm{l}$ of saline $(0.9 \% \mathrm{NaCl})$ per side was delivered bilaterally into the mPFC via an infusion pump using a 5- $\mu \mathrm{l}$ Hamilton (Reno, NV) syringe connected to polyethylene tubing (PE20; Becton Dickinson, Franklin Lakes, NJ). Infusions $(0.5 \mu \mathrm{l} / \mathrm{min})$ were administered over 60 seconds, and the injection needles (28G, 1.5-mm insertion length) were left in the guide cannula for an additional 120 seconds to allow for diffusion of the drug from the needle tip.
Intrathecal Administration. Intrathecal injections, which lasted for about 5 minutes, were performed on rats 2-3 weeks post CCI surgery, as previously described (Mestre et al., 1994). Rats were anesthetized with $5 \%$ isoflurane (in $\mathrm{O}_{2}$, to effect) and the dorsal pelvic area was shaved and cleaned with $70 \%$ ethyl alcohol. The intrathecal injections occurred under anesthesia (3\% isoflurane in $\mathrm{O}_{2}$, to effect). The lumbar region was elevated by placing the rat on a fixed $50-\mathrm{ml}$ conical tube. The hip bone (iliac crest) was identified to assist in locating the L6 vertebrae. Reagents were prepared in sterile saline $(0.9 \% \mathrm{NaCl})$ and injected into the space between the L4 and L5 vertebrae using a 25- $\mu$ l Hamilton syringe and a $30 \mathrm{G}$ needle. A volume of $20 \mu \mathrm{l}$ of NYX-2925 $(0.01-1000 \mu \mathrm{g})$, injectable sterile saline $(0.9 \% \mathrm{NaCl})$, or $\mathrm{CPP}(50 \mu \mathrm{g})$ was administered over 60 seconds, and the injection needle was left in the site for an additional 15 seconds to allow for diffusion of the drug from the needle tip.

Intravenous Administration. For administration of the positive control in the rat tail flick experiment, the rat was heated to a temperature of around $40^{\circ} \mathrm{C}$ by being placed in a thermostatically warmed "hot box" to dilate the lateral tail veins. For injection, the rat was placed in a restrainer and an injection bolus (buprenorphine, $1 \mathrm{ml} / \mathrm{kg}$ ) was administered using a $25 \mathrm{G}$ needle.

Animals and Housing. Male, 2-3-month old Sprague-Dawley rats [Envigo (Indianapolis, IN) or Charles River Laboratories (O'Fallon, MO)] weighing 250-350 g were used. All animal handling and experimental protocols were approved by the Institutional Animal Care and Use Committee at Northwestern University or at PsychoGenics, Inc. Rats were housed three per cage with Envigo Tek-Fresh bedding, supplemented with Enviro-Dri bedding (Shepherd Specialty Papers, Watertown, TN); maintained on a 12:12 light:dark cycle (lights on at $6 \mathrm{AM}$ ); and given ad libitum access to Purina (St. Louis, MO) laboratory chow and tap water throughout the study, unless indicated otherwise. All behavioral experiments were carried out between $8 \mathrm{AM}$ and $4 \mathrm{PM}$ in testing rooms at the same animal facility.

Plasma and Spinal Cord Pharmacokinetics. To guide the dosage choice for intrathecal administration studies, a pharmacokinetic study was completed to assess dose levels reaching the spinal cord after oral administration. Determination of plasma and cerebrospinal fluid pharmacokinetics of NYX-2925 after oral administration was performed by Sai Life Sciences and described previously (Khan et al., 2018). Fasted, naïve male rats (Global, Maharashtra, India) were dosed with NYX-2925 [10 mg/kg, $10 \mathrm{ml} / \mathrm{kg}$, per os (by mouth; PO)]. Next, plasma and spinal cord were collected at $0.5,1,2,4,8$, and 24 hours post dose. Blood samples $(\sim 125 \mu \mathrm{l})$ were collected in K2EDTA tubes. Samples were centrifuged ( $4000 \mathrm{rpm}, 10$ minutes, $4^{\circ} \mathrm{C}$ ), and plasma was then extracted with acetonitrile for bioanalysis. Spinal cord samples were homogenized in ice-cold phosphate-buffered saline, and homogenates were stored at $-80^{\circ} \mathrm{C}$ until analysis. On the day of the assay, homogenates were thawed on ice and extracted with acetonitrile. NYX-2925 levels were quantified by liquid chromatography-tandem mass spectrometry and noncompartmental analysis (Phoenix WinNonlin version 6.3; Certara, St. Louis, MO). NYX-2925 concentrations were within the linear range of the standard curve. The lower limit of detection for this assay was $10.29 \mathrm{nM}$.

Animal Models of Acute, Persistent, and Neuropathic Pain. For the assessment of NYX-2925 efficacy in spontaneous persistent pain, the rat formalin model (Dubuisson and Dennis, 1977) was used. The rat tail flick test (D'Amour and Smith, 1941) was used as the acute nociceptive pain model. Chronic constriction injury of the sciatic nerve (Bennett and Xie, 1988) and STZ-induced diabetic neuropathy (Morrow, 2004) were used as models of neuropathic pain. For models requiring surgery, isoflurane anesthesia was chosen as the preferred method to eliminate the interference of the injectable anesthetics (e.g., ketamine) with the target of interest.

Chronic Constriction Injury of the Sciatic Nerve. CCI of the common sciatic nerve was performed as previously described (Bennett and Xie, 1988). In brief, rats were anesthetized using isoflurane ( $3 \%$ in $\mathrm{O}_{2}$, to effect), and an incision ( $1.0 \mathrm{~cm}$ in length) was made with a scalpel blade dorsally through the skin on the 
right hind limb parallel and posterior to the femur. Using blunt scissors, the biceps femoris and gluteus superficialis muscles were separated. The common sciatic nerve was isolated, exposed, and loosely ligated with four ligatures (chromic gut 5-0; Ethicon, Johnson and Johnson, New Brunswick, NJ) placed $1 \mathrm{~mm}$ apart. The same procedure was performed for the sham surgery except the sciatic nerve was left intact and not ligated. Both CCI thermal and mechanical acute dose studies were performed at Aptinyx, Inc. (Evanston, IL), whereas repeated-dose mechanical hypersensitivity studies were performed by PsychoGenics, Inc. Two to 3 weeks post surgery, rats were measured for baseline thermal hyperalgesia or mechanical hypersensitivity of the ipsilateral paw followed by dosing and testing.

Streptozotocin-Induced Diabetic Neuropathy. To induce diabetic neuropathy, rats were injected with STZ at $20 \mathrm{mg} / \mathrm{kg}$ i.p. once daily for 5 consecutive days [modified from Morrow (2004)]. Following the first STZ injection, rats were given tap water supplemented with $10 \%$ sucrose (15 g/l) until 48 hours after the last STZ injection to limit early mortality. Using a restrainer, blood glucose levels were assessed via lateral tail vein puncture prior to the test day to evaluate the extent of hyperglycemia. Less than $100 \mu \mathrm{l}$ of blood was withdrawn. Rats with blood glucose levels below $15 \mathrm{mM}(280 \mathrm{mg} / \mathrm{dl})$ were excluded from the study. Baseline mechanical hypersensitivity of the right paw, as measured with von Frey filaments, was assessed 4 weeks after the first STZ injection, followed by dosing and mechanical sensitivity studies.

Thermal Hyperalgesia (Hargreaves Test). Thermal hyperalgesia of the hind paws was measured using an Ugo Basile plantar apparatus (Stoelting Company, Chicago, IL) and as described by Hargreaves et al. (1988). Animals were placed in plastic cages on the surface of a glass plate. After a 15-minute acclimation period, a radiant stimulus was applied from beneath to the middle of the plantar surface. When the animal withdrew its paw, the heat source was stopped and paw withdrawal latency (PWL) was recorded. A cutoff of 30 seconds was used to prevent potential tissue damage. The intensity of the heat stimulus was adjusted to evoke an average withdrawal response of approximately 20 seconds for the shamoperated rats (De Vry et al., 2004). Five PWL measurements per ipsilateral hind paw were collected 5 minutes apart. Before test day, all CCI rats were evaluated for thermal hyperalgesia. Only CCI rats with PWL $\leq 11$ seconds were used for testing (De Vry et al., 2004). The reported PWL was an average of three measurements after the highest and the lowest values were eliminated.

Mechanical Hypersensitivity (von Frey) Test. Mechanical hypersensitivity was measured by applying von Frey filaments (North Coast Medical, Morgan Hill, CA) of ascending stiffness (2, 4, 6, 8, 10, and $15 \mathrm{~g}$ ) to the plantar surface of the ipsilateral hind paw. Baseline and post-treatment paw withdrawal threshold (PWT) were determined using this method. Animals were allowed to acclimate to the experimental room for 1 hour and were then habituated for an additional 15 minutes to the observation chamber prior to each test session.

Each von Frey filament was applied perpendicular to the plantar surface of the paw ipsilateral to CCI surgery with sufficient force to cause slight buckling and was held in place for an additional 6 seconds.
A positive response was defined as sharp paw withdrawal. Fifty percent PWT in grams was calculated based on the Chaplan method (Chaplan et al., 1994). At the baseline evaluation post CCI, any rat with PWT above $5 \mathrm{~g}$ was excluded from the study (approximately $10 \%-15 \%)$.

Von Frey testing groups were organized such that the average $50 \%$ PWT (grams) obtained from the baseline measurement was similar for each treatment group. The studies were conducted so that the investigator performing the testing was blind to treatment group. The timing of von Frey testing relative to the dosing of NYX-2925 for each behavioral experiment measuring mechanical analgesia is shown in Table 1.

Cannulae Implantation. mPFC cannulation occurred immediately after CCI surgery. Using a Kopf (Tujunga, CA) stereotaxic device, the skull was secured parallel to the frame under isoflurane anesthesia ( $3 \%$ in $\mathrm{O}_{2}$, to effect). Bilateral guide cannulae (22 gauge, $1.5 \mathrm{~mm}$ center-to-center distance; Plastics One, Roanoke, VA) were implanted above the mPFC (from bregma: $2.7 \mathrm{~mm}$ anterior-posterior, $\pm 0.5 \mathrm{~mm}$ medial-lateral, $-3.0 \mathrm{~mm}$ dorsal-ventral) in accordance with the Paxinos and Watson atlas for a level-skull preparation (Paxinos and Watson, 1998; Burgdorf et al., 2013). Guide cannulae were secured in a dental acrylic headcap via small screws. After surgery, internal dummy cannulae were inserted into the guide cannulae. The total surgery duration was about 35-45 minutes. After surgery, animals were housed one per cage.

To verify cannulae placement after the completion of behavioral testing, rats were euthanized, and brains were snap frozen on dry ice and stored at $-80^{\circ} \mathrm{C}$ until histologic analysis. Thirty-micrometer brain sections were used for histology as described previously (Burgdorf et al., 2001).

Tail Flick Test. Acute nociception was measured using withdrawal latencies of the tail from a noxious radiant heat source. The Ugo Basile tail flick apparatus (Stoelting Company) was used to determine thermal pain latency. Stimulation parameters were set such that the average tail withdraw latency was between 3 and 5 seconds in naive rats (infrared intensity: 50; cutoff latency: 15 seconds). Rats were acclimated to the experiment room 1 hour prior to testing. Baseline tail flick values (1 value/rat) were obtained from all rats prior to dosing. Fifteen minutes post baseline measurements, rats were dosed with the test compound, vehicle, or buprenorphine $\mathrm{HCl}(1 \mathrm{mg} / \mathrm{kg}$, i.v.), and post dose values were taken 1 hour later.

Formalin-Induced Persistent Pain Model. Formalin-induced persistent pain was measured as previously described (Hsieh et al., 2010). In brief, clear Plexiglas chambers were outfitted with observation mirrors underneath the cage floor. Rats were orally dosed with vehicle $(0.5 \% \mathrm{CMC}, 2 \mathrm{ml} / \mathrm{kg})$, gabapentin $(150 \mathrm{mg} / \mathrm{kg})$, or NYX-2925 $(0.1,1$, or $10 \mathrm{mg} / \mathrm{kg})$ and placed individually in the observation boxes to acclimate. Fifteen minutes after test compound administration, $50 \mu \mathrm{l}$ of $5 \%$ formalin solution was injected subcutaneously into the dorsal side of the right paw, and rats were placed back into the observation boxes. Pain behavior was recorded by video camera for 60 minutes, and total pain responses (flinching, jerking, lifting, shaking, licking, and biting) were quantified by an investigator blind to treatment. Formalin nociception consists of an early phase (0-10 minutes, phase

\section{TABLE 1}

Time course of drug or vehicle administration and von Frey testing

\begin{tabular}{|c|c|c|c|}
\hline Experiment & $\begin{array}{c}\text { NYX-2925 } \\
\text { Administration }\end{array}$ & Von Frey Testing & Figure \\
\hline CCI single administration & Day 0 & $1 \mathrm{~h}, 24 \mathrm{~h}$, and $1 \mathrm{wk}$ post administration & 1B \\
\hline CCI single administration & Day 0 & $1 \mathrm{~h}$ post administration & $2 \mathrm{~A}$ \\
\hline CCI repeat administration, therapeutic doses & Days $0-13$ & $24 \mathrm{~h}$ following administration and on days $1,3,6,9,12$, and 14 & $2 \mathrm{~B}$ \\
\hline CCI repeat administration, subtherapeutic doses & Days $0-8$ & $1 \mathrm{~h}$ post administration on days 1,5 , and 8 & $2 \mathrm{C}$ \\
\hline $\mathrm{CCI} \mathrm{mPFC}$ infusion & Day 0 & $20 \mathrm{~min}, 24 \mathrm{~h}$, and $1 \mathrm{wk}$ post administration & $6 \mathrm{~A}$ \\
\hline CCI intrathecal injection & Day 0 & $30-45$ min post administration & $6 \mathrm{~B}$ \\
\hline CCI single administration, CPP pretreatment & Day 0 & $1 \mathrm{~h}, 24 \mathrm{~h}$ post- NYX-2925 administration & 8 \\
\hline STZ-induced diabetic neuropathy & Day 0 & $1 \mathrm{~h}, 24 \mathrm{~h}$, and $1 \mathrm{wk}$ post administration & 3 \\
\hline
\end{tabular}


I) followed by brief quiescence and a late phase (20-50 minutes, phase II) (Dubuisson and Dennis, 1977). The formalin late phase represents tonic and persistent pain (Chaplan et al., 1997). The 30-55-minute period of phase II was scored by an investigator blind to treatment. Scoring was performed in 5-minute bins, i.e., five observation periods in total. The number of pain-evoked responses were summed for all 5 -minute bins for each rat and then averaged for each treatment group (Hsieh et al., 2010).

Ultrasonic Vocalization Assay. Using a separate set of CCI rats, the ultrasonic vocalization (USV) assay was performed at 3 weeks post CCI as described previously (Burgdorf et al., 2011a). A week prior to the USV study, rats were measured for mechanical hypersensitivity using von Frey filaments. Prior to the ultrasonic vocalization test, rats were habituated for 3 consecutive days by light touch handling that did not induce USVs (Burgdorf and Panksepp, 2001). On the experiment day, Rats were administered NYX-2925 (1 or $10 \mathrm{mg} / \mathrm{kg}$, $1 \mathrm{ml} / \mathrm{kg}$, PO) or vehicle $(0.5 \% \mathrm{CMC} ; 1 \mathrm{ml} / \mathrm{kg}, \mathrm{PO}) 1$ hour prior to testing. The assay consisted of 3 minutes of heterospecific rough-and-tumble play with alternating 15-second blocks of heterospecific play and 15 seconds of no stimulation for a total of six trials of each type (Burgdorf et al., 2011a). High-frequency USVs were recorded and analyzed by sonogram by an experimenter who was blind to treatment condition. Immediately after the 3-minute test session, the latency (in seconds) of the rat to approach the experimenter's hand to receive heterospecific play was also measured (Burgdorf et al., 2011a).

Statistical Analysis. Statistical analysis was carried out using GraphPad Prism, version 6.07 (GraphPad Software, San Diego, CA). Statistical significance of group mean differences was measured by one-way analysis of variance, followed by a Bonferroni post-hoc test for all studies, except for the CCI repeat subtherapeutic dose study, for which between-subject score one-way analysis of variance, followed by Fisher's post-hoc test, was performed. In all cases, $P<0.05$ was considered to be statistically significant.

\section{Results}

Because chronic pain is a multifaceted disease that cannot be adequately captured via a single model, the analgesic effect of NYX-2925 was tested in CCI- and diabetes-induced neuropathic pain models. In the CCI model, the analgesic ability of NYX-2925 to alleviate thermal hyperalgesia and mechanical hypersensitivity was examined. NYX-2925 attenuated thermal nociception when tested at 1 hour after oral administration. The analgesic effects of NYX-2925 administration were examined over a wide dose range at three time points after a single administration (1 hour, 24 hours, and 1 week) or after 2 weeks of daily dosing. Within the CCI model, additional experiments were completed to better understand the site of drug action as well as the dependence upon NMDA receptors. To assess the analgesic effects of NYX-2925 in a second neuropathic pain model, the STZ-induced diabetic neuropathy model was used. NYX-2925 analgesic efficacy was also tested in the formalin model of persistent pain and in the tail flick test of acute nociceptive pain. In addition, because neuropathic pain involves both sensory and affective components, the effects of NYX-2925 on emitted USVs were assessed in the heterospecific rough-and-tumble-play model in animals with CCI-induced neuropathic pain.

Acute administration of NYX-2925 has significant thermal and mechanical analgesic effects in the rat CCI model of neuropathic pain.

CCI is a model of neuropathic pain induced by peripheral nerve injury (Bennett and Xie, 1988). A cohort of sham and CCI-operated rats were generated. Thermal hyperalgesia was
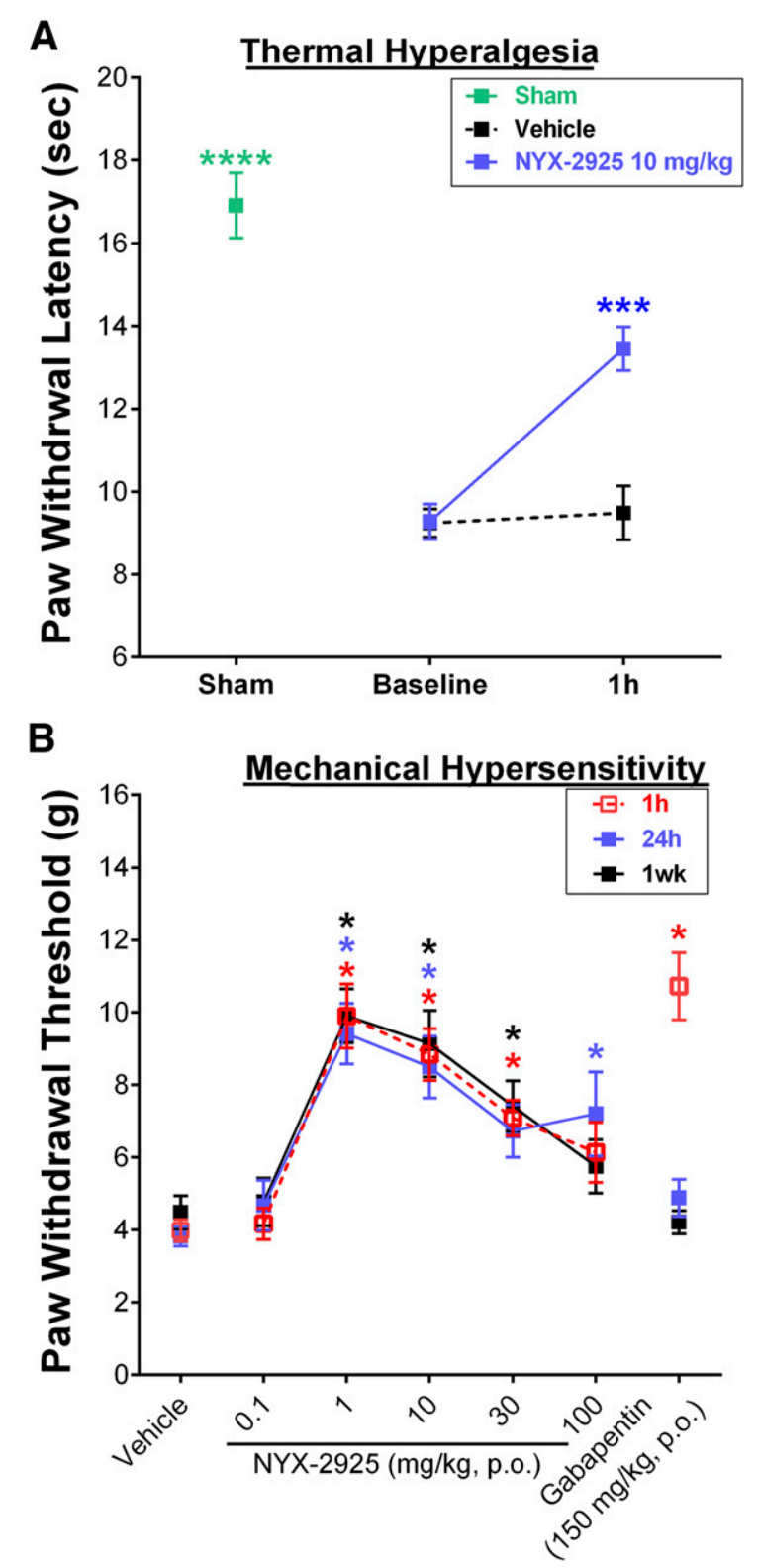

Fig. 1. Administration of NYX-2925 produced thermal and mechanical analgesia in the CCI model of neuropathic pain. (A) Animals were administered a single dose of vehicle or NYX-2925 $(10 \mathrm{mg} / \mathrm{kg})$ and assessed for thermal analgesic effect, as measured by PWL at 1 hour post drug administration. A single administration of NYX-2925 $(10 \mathrm{mg} / \mathrm{kg})$ at the 1-hour time point significantly increased PWL when compared with the vehicle control group $(P<0.05)$. The sham vehicle-treated rat PWL value was equal to 16.9 seconds $(P>0.05)$. (B) Animals were administered a single dose of vehicle, NYX-2925 $(0.1,1,10,30$, or $100 \mathrm{mg} / \mathrm{kg})$, or gabapentin $(150 \mathrm{mg} / \mathrm{kg})$ and assessed for analgesic effect, as measured by PWT, 1 hour, 24 hours, or 1 week post drug administration. A single administration of NYX-2925 $(1,10$, or $30 \mathrm{mg} / \mathrm{kg})$ at the 1 -hour time point significantly increased PWT when compared with the vehicle control group $(P<0.05)$. At the 24-hour time point, NYX-2925 (1, 10, or $100 \mathrm{mg} / \mathrm{kg}$ ) significantly increased PWT versus vehicle. The analgesic effect of NYX-2925 lasted up to 1 week for dose levels 1,10 , and $30 \mathrm{mg} / \mathrm{kg}$. NYX-2925 at $100 \mathrm{mg} / \mathrm{kg}$ was not analgesic at the 1 -week time point $(P>$ $0.05)$. NYX-2925 at the lowest dose $(0.1 \mathrm{mg} / \mathrm{kg})$ was not analgesic at any of the time points ( 1 hour, 24 hours, and 1 week) tested $(P>0.05) . N=10-11$ animals per group.

evaluated 2 weeks after surgery and when neuropathic pain was established and stable. Using a plantar test apparatus, sham and CCI rats were evaluated for baseline thermal 
A

\section{Single Administration}

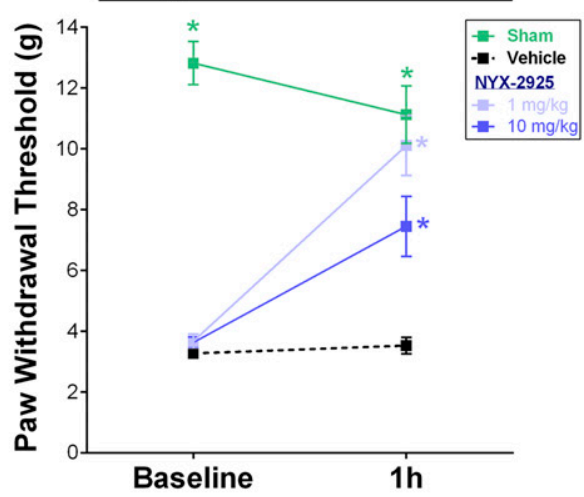

B

\section{Repeat Administration} Therapeutic Doses

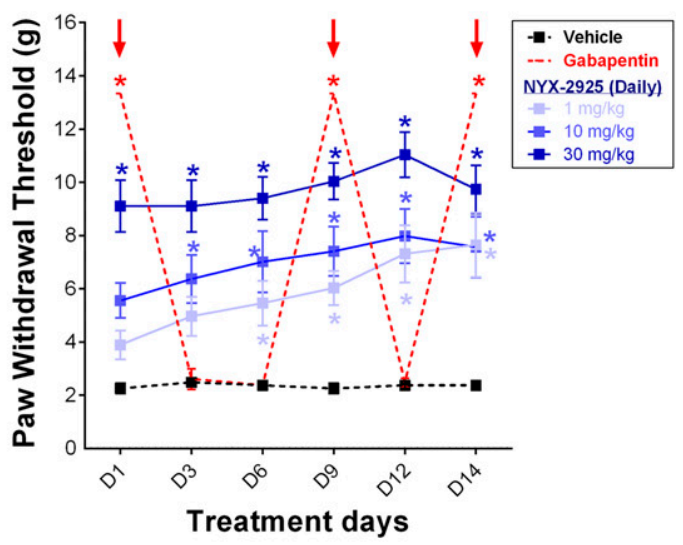

C

Repeat Administration Sub-Therapeutic Doses

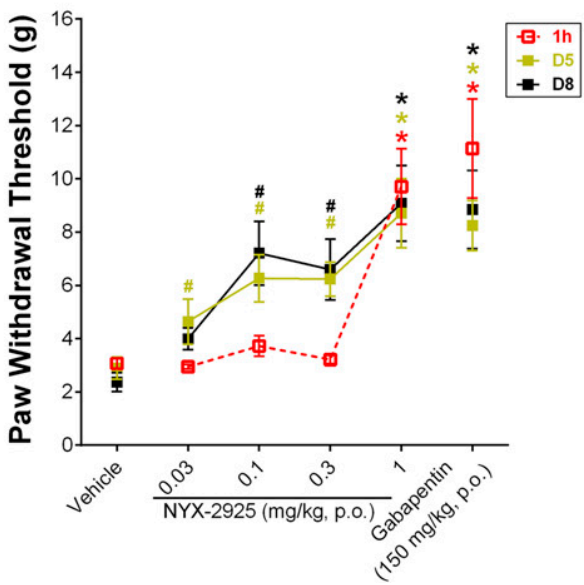

Fig. 2. Administration of NYX-2925 produced robust, dose-dependent, and long-lasting mechanical analgesia in the CCI model of neuropathic pain. (A) CCI rats were administered a single dose of vehicle or NYX-2925 $(10 \mathrm{mg} / \mathrm{kg})$ and assessed for analgesic effect, as measured by PWT at 1 hour post drug administration. A single administration of NYX-2925 $(10 \mathrm{mg} / \mathrm{kg})$ at the 1-hour time point significantly increased PWT when compared with the vehicle control group $(P<0.05)$. Sham vehicle-treated PWT was similar to its baseline value and was equal to $11.12 \mathrm{~g}(P>0.05)$. (B) Daily administration of NYX-2925 $(1,10$, or $30 \mathrm{mg} / \mathrm{kg})$ maintained analgesic efficacy over the course of 2 weeks. Animals were dosed daily with vehicle or NYX-2925 (1, 10, or $30 \mathrm{mg} / \mathrm{kg})$ for 13 consecutive days and nociception as measured by PWL in seconds. As shown in Fig. 1A, sham rats showed high PWL $(16.9 \pm 0.6, n=9)$. In contrast, CCI rats were hyperalgesic and had lower PWL $(9.2 \pm 0.3, n=15)$. On test day (day 15 post surgery), CCI rats with baseline PWL $\leq 11$ were dosed orally with either vehicle (0.5\% CMC) or NYX-2925 at $10 \mathrm{mg} / \mathrm{kg}$. In contrast to sham rats, CCI vehicle-treated rats showed thermal hyperalgesia as demonstrated by low PWL $(9.5 \pm 0.7, n=7)$. NYX-2925 administration attenuated thermal hyperalgesia and resulted in significantly higher PWL $(13.5 \pm 0.5, n=8)$ when tested at 1 hour $[F(4,33)=$ $35.90, P<0.0001]$.

Another cohort of rats underwent CCI surgery. Rats with established and stable mechanical allodynia, as measured by PWT in grams, were dosed once with NYX-2925 $(0.1-100 \mathrm{mg} / \mathrm{kg})$ and tested 1 hour, 24 hours, and 1 week post administration. A naïve rat that has not undergone the CCI surgery will have a PWT of $15 \mathrm{~g}$ (Mills et al., 2012). This value represents the highest possible withdrawal threshold using filaments of the size used in this study. Comparatively, as shown in Fig. 1B, approximately 3 weeks after CCI surgery, vehicle-treated rats showed mechanical allodynia as demonstrated by low PWTs of approximately 4 g. NYX-2925 administration resulted in significant and longlasting analgesia when compared with the vehicle group at all three time points tested ( 1 hour: $F(6,65)=15.22, P<0.0001$; 24 hours: $F(6,65)=7.761, P<0.0001 ; 1$ week: $F(6,65)=12.39$, $P<0.0001)$. Dose levels of 1,10 , and $30 \mathrm{mg} / \mathrm{kg}$ increased the PWT significantly $(P<0.001)$ at all three time points tested. NYX-2925 demonstrated an inverted U-shaped dose response with maximal analgesia observed at $1-10 \mathrm{mg} / \mathrm{kg}$. Acute administration of $0.1 \mathrm{mg} / \mathrm{kg}$ NYX-2925 was ineffective at all three time

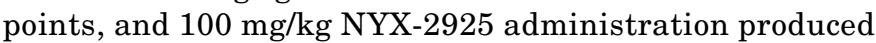
analgesia at the 1- and 24-hour time points, but not the 1-week time point when compared with the vehicle-treated group (Fig. 1B). Gabapentin, the positive control, showed significant but short-lasting analgesia only at the 1-hour time point $(P<0.0001)$.

To include a sham-operated group, a separate cohort of CCI and sham rats were generated (Fig. 2A). As expected, the vehicle-administered sham rats had a high baseline PWT of

were tested for mechanical hypersensitivity 24 hours after dosing. A separate group of animals were dosed with gabapentin $(100 \mathrm{mg} / \mathrm{kg})$ on days 1,9 , and 14 . Vehicle was administered to these rats on days between tests so that all groups were identically handled. Gabapentin-treated animals were tested for mechanical hypersensitivity 1 hour after dosing. NYX-2925 administration significantly increased PWT when compared with vehicle control group on all test days (days $1,3,6,9,12$, and $14: P<$ 0.0001 ). The analgesic effects of gabapentin (dosed on D1, D9, and D14; red arrows) were short-lived, with loss of efficacy observed at 48 hours post administration (D3, D6, and D12). $N=10$ animals per group. (C) Daily dosing of subtherapeutic NYX-2925 doses increased analgesic efficacy to therapeutic levels. Animals were treated daily with vehicle or NYX-2925 $(0.03,0.1,0.3$, or $1 \mathrm{mg} / \mathrm{kg})$ and assessed 1 hour after administration on D1, D5, and D8. A separate group of CCI animals were dosed with gabapentin only on test days (D1, D5, and D8) and assessed for mechanical hypersensitivity 1 hour after dosing. Daily dosing of NYX-2925 $(0.03$, 0.1 , and $0.3 \mathrm{mg} / \mathrm{kg}$ ) increased the PWT when compared with the previous test day. NYX-2925 at its therapeutic dose $(1 \mathrm{mg} / \mathrm{kg})$ showed a consistent increase in PWT when compared with vehicle for all test days $(P<0.05)$. Animals dosed with gabapentin showed significant analgesia on each testing day $(P<0.05) . N=4-6$ animals per group. Between-subjects score two-way analysis of variance followed by post-hoc Fisher's test. Data represent means \pm S.E.M. *Statistically significant differences when compared with the vehicle group at the same time point $(P<0.05)$; " statistically significant differences when compared with the same group at a different test day $(P<0.05)$. 
$12.8 \pm 0.7$ [day 14 (D14) post surgery] and PWT of $11.1 \pm 0.9$ measured 1 hour after vehicle treatment on the experiment day (D19 post surgery, $n=12$ ). In contrast, vehicle-treated CCI rats were allodynic and had low PWT both at baseline $(3.3 \pm 0.1, n=12)$ and on test days $(3.5 \pm 0.3, n=12)$. Compared with vehicle-treated CCI rats, the NYX-2925-treated CCI rats showed significantly higher PWT at both $1 \mathrm{mg} / \mathrm{kg}$ $(10.1 \pm 1.0, n=9)$ and $10 \mathrm{mg} / \mathrm{kg}(7.4 \pm 1.0, n=9)$ when tested at 1 hour after oral administration $[F(3,38)=18.89, P<0.0001]$. These data demonstrate the reproducibility of NYX-2925 analgesic effects similar to that seen in Fig. 1B.

Daily Administration of NYX-2925 Has a Sustained and Significant Analgesic Effect in the Rat Chronic Constriction Model of Neuropathic Pain. To evaluate the effect of chronic dosing of NYX-2925 on neuropathic pain, CCI surgery was performed on a separate set of animals. Once mechanical allodynia was established and stabilized, rats were randomly assigned to dosing groups. Animals were dosed daily from days 0 to 13 with vehicle $(0.5 \% \mathrm{CMC}, \mathrm{PO})$ or NYX$2925(1,10$, or $30 \mathrm{mg} / \mathrm{kg}, \mathrm{PO})$ for 13 consecutive days and were tested for mechanical hypersensitivity 24 hours after dosing on days $1,3,6,9,12$, and 14 . Animals in the positive control group were dosed with gabapentin $(100 \mathrm{mg} / \mathrm{kg})$ on days 1,9 , and 14, and tested 1 hour post dosing. To maintain similar handling between groups, vehicle was administered on non-test days to rats that received gabapentin. Animals administered NYX-2925 demonstrated a significantly increased PWT compared with the vehicle-treated rats on all test days $[\mathrm{D} 1: F(4,45)=57.67$, $P<0.0001 ; \mathrm{D} 3: F(4,45)=15.47, P<0.0001 ; \mathrm{D} 6: F(4,45)=16.93$, $P<0.0001$; D9: $F(4,45)=49.42, P<0.0001 ;$ D12: $F(4,45)=$ $23.75, P<0.0001$; and D14: $F(4,45)=21.97, P<0.0001]$. Daily dosing of NYX-2925 at all doses significantly increased the PWT $(P<0.001)$ in a dose-dependent manner (Fig. 2B). This analgesic effect was sustained at all time points (D1, D3, D6, D9, D12, and D14). Gabapentin at $100 \mathrm{mg} / \mathrm{kg}$ showed significant but short-lasting analgesia, with analgesic effects seen only on dosing days (D1, D9, and D14).

Daily Administration of Subtherapeutic NYX-2925 Doses Improves Mechanical Hypersensitivity in the Rat CCI Model of Neuropathic Pain. The acute administration study demonstrated that NYX-2925 was not analgesic at the lowest dose $(0.1 \mathrm{mg} / \mathrm{kg})$ tested. To assess whether repeat administration of subtherapeutic doses may become effective, subtherapeutic doses were administered to CCI rats. Animals were dosed daily for 8 days with vehicle or NYX-2925 $(0.03,0.1,0.3$, or $1 \mathrm{mg} / \mathrm{kg})$ and tested 1 hour after dosing on D1, D5, and D8. Animals in the positive control group were dosed with gabapentin $(150 \mathrm{mg} / \mathrm{kg}) 1$ hour prior to testing on each day. As shown in Fig. 2C, repeat administration of NYX-2925 at $1 \mathrm{mg} / \mathrm{kg}$ was analgesic $(P<0.05)$ at all three time points tested (D1, D5, D8) when compared with the vehicle group $[D 1: F(5,25)=15.86, P<0.0001 ;$ D5: $F(5,24)=5.323, P=0.01$; D8: $F(5,24)=5.650, P=0.001]$. Repeat administration of subtherapeutic NYX-2925 doses $(0.1$ or $0.3 \mathrm{mg} / \mathrm{kg}$ ) showed a trend toward analgesia. The PWT of NYX-2925 at $0.1 \mathrm{mg} / \mathrm{kg}$ increased from $3.72 \pm 0.39$ (D1) to $7.21 \pm 1.2$ (D8) $(P<0.05)$. The PWT of NYX-2925 at $0.3 \mathrm{mg} / \mathrm{kg}$ also increased from $3.22 \pm 0.15$ (D1) to $6.6 \pm 1.14$ (D8) $(P<0.05)$.

Acute Administration of NYX-2925 Has a Significant and Long-Lasting Analgesic Effect in the Rat STZ-Induced Diabetic Neuropathy Model. Administration of STZ induces a diabetic-like state in rodents that, over time, produces pain

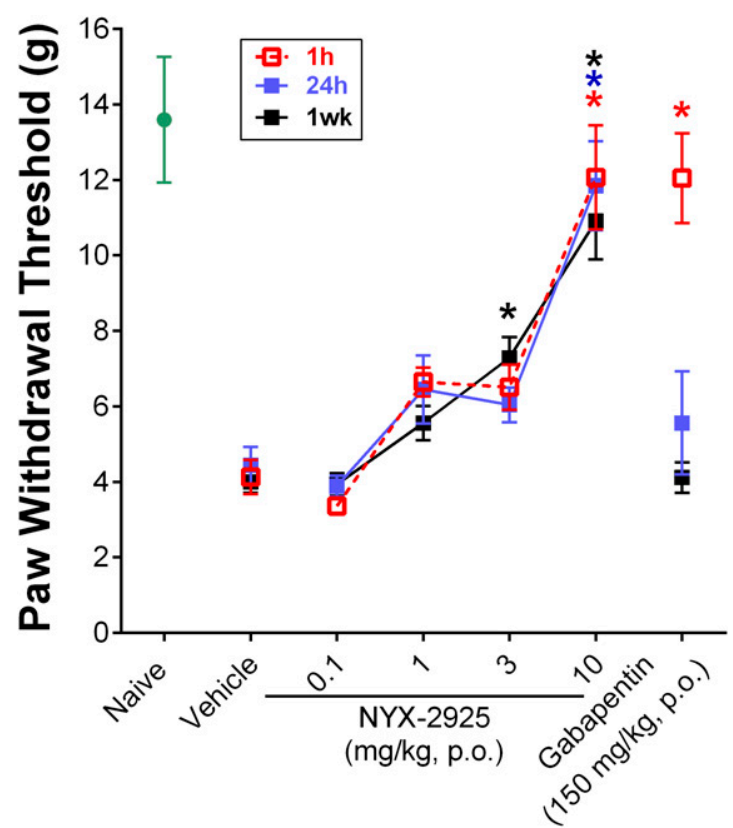

Fig. 3. A single administration of NYX-2925 produced significant and long-lasting mechanical analgesia in the STZ-induced diabetic neuropathy model. Neuropathic pain was measured 4 weeks post STZ. Animals were administered a single dose of vehicle, NYX-2925 $(0.1,1,3$, or $10 \mathrm{mg} / \mathrm{kg}$, $\mathrm{PO})$, or gabapentin (150 mg/kg, PO) and assessed for analgesic effects at 1 hour, 24 hours, or 1 week post drug administration. NYX-2925 at the 1-hour time point significantly increased PWT at the 1-, 3-, and 10-mg/kg dose levels versus vehicle $(P<0.05)$. At the 24 -hour time point, $10 \mathrm{mg} / \mathrm{kg}$ NYX-2925 significantly increased PWT versus vehicle $(P<0.05)$. The analgesic effect of NYX-2925 lasted up to 1 week, with significant increase in PWT seen with 3 and $10 \mathrm{mg} / \mathrm{kg}$ versus vehicle $(P<0.05)$. Gabapentin increased PWT at the 1-hour time point only $(P<0.05) . N=6-8$ animals per group. Data represent means \pm S.E.M. *Statistically significant differences when compared with the vehicle group at the same time point $(P<0.05)$.

similar to that seen in human diabetic neuropathy (Morrow, 2004). The analgesic effect of NYX-2925 was evaluated in the rat STZ-induced diabetic neuropathy model after the establishment of mechanical hypersensitivity, as measured by paw withdrawal threshold. On the test day, animals were orally dosed with vehicle $(0.5 \% \mathrm{CMC})$, NYX-2925 $(0.1,1,3$, or $10 \mathrm{mg} / \mathrm{kg})$, or gabapentin $(150 \mathrm{mg} / \mathrm{kg})$. Testing occurred 1 hour, 24 hours, and 1 week post treatment. As shown in Fig. 3, NYX-2925 significantly reversed mechanical allodynia at the 1-hour $[F(5,36)=21.34], 24$-hour $[F(5,39)=7.248]$, and 1-week $[F(5,38)=23.69]$ time points $(P<0.0001$ for all three time points). After a single dose, $10 \mathrm{mg} / \mathrm{kg}$ NYX-2925 produced significant analgesia at 1 hour $(P<0.0001), 24$ hours $(P<$ $0.001)$, and 1 week $(P<0.0001)$ as compared with the vehicle control group. NYX-2925 at $3 \mathrm{mg} / \mathrm{kg}$ also produced significant analgesia at the 1 -week time point $(P<0.001)$. NYX-2925 at the lowest dose $(0.1 \mathrm{mg} / \mathrm{kg})$ was not analgesic at any of the time points tested $(P>0.05)$. Gabapentin produced analgesic activity when tested 1 hour post dose $(P<0.0001)$ but not at the 24-hour or 1-week time points $(P>0.05)$.

The results from thermal hyperalgesia experiments conducted in the STZ-induced diabetic rats were too variable and, hence, are not reported. The literature has previously reported high variability in thermal hyperalgesia in STZ-induced diabetes (Malcangio and Tomlinson, 1998; Khan et al., 2002; Newton et al., 2017). Although some investigators have reported an effect (Mak et al., 2015), the STZ doses used were 


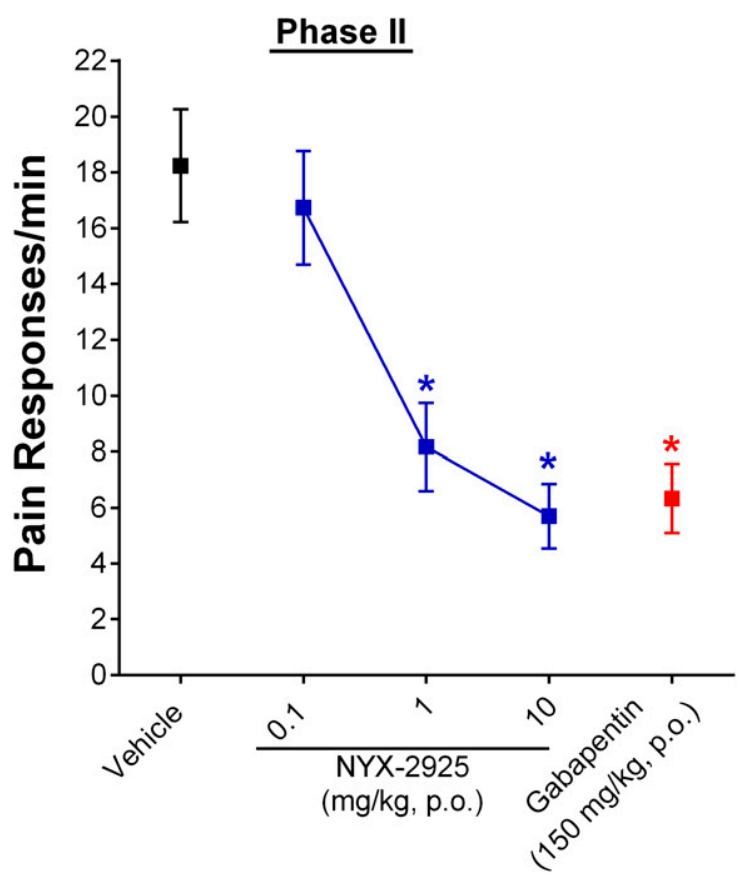

Fig. 4. Naïve animals were administered vehicle, NYX-2925 $(0.1,1$, or $10 \mathrm{mg} / \mathrm{kg}, \mathrm{PO})$, or gabapentin $(150 \mathrm{mg} / \mathrm{kg}, \mathrm{PO}) 15$ minutes prior to formalin administration (50 $\mu \mathrm{l}$ of $5 \%$ formalin, s.c.) into the dorsal right paw. Pain reactions (flinching, jerking, lifting, shaking, licking, and biting) occurring between minutes 30 and 55 were scored in 5-minute bins. NYX-2925 (1 and $10 \mathrm{mg} / \mathrm{kg}$ ) and gabapentin $(150 \mathrm{mg} / \mathrm{kg}$ ) significantly reduced the average number of pain reactions versus vehicle $(P<0.05)$. NYX-2925 at $0.1 \mathrm{mg} / \mathrm{kg}$ was ineffective. $N=5-6$ animals per group. Binned data represent the average of all pain reactions \pm S.E.M. during $30-55$ minutes post formalin injection per group. *Statistically significant differences when compared with the vehicle group at the same time point $(P<0.05)$.

much higher $(160 \mathrm{mg} / \mathrm{kg}$, i.p.) than what was used in the current study.

Acute Administration of NYX-2925 Significantly Reduces Total Pain Responses in the Second Phase of the Rat Formalin Model. To evaluate the effects of NYX-2925 in a nonevoked persistent pain model, the formalin model was used (Dubuisson and Dennis, 1977; Wood et al., 2008; Hsieh et al., 2010). NYX-2925 $(0.1,1$, or $10 \mathrm{mg} / \mathrm{kg})$, vehicle $(0.5 \%$ $\mathrm{CMC})$, or gabapentin $(150 \mathrm{mg} / \mathrm{kg})$ was administered via oral gavage 15 minutes prior to a subcutaneous hind paw injection of $5 \%$ formalin. The pain response after formalin administration consists of two well described phases: phase I and phase II (Abbott et al., 1995). Phase II starts approximately 20 minutes after injection, persists for approximately 30 minutes, and is considered to have a centralized component (Ellis et al., 2008). NYX-2925 dose-dependently reduced total pain responses in phase II $[F(4,140)=13.21, P<0.0001]$ (Fig. 4). The average pain score for the vehicle group in phase II was $18.24 \pm 2.02$. That score was reduced to $8.17 \pm 1.57$ and $5.70 \pm 1.16$ following administration of NYX-2925 at 1 and $10 \mathrm{mg} / \mathrm{kg}$, with $P<0.001$ and $P<0.0001$, respectively. Treatment with the positive control gabapentin also significantly reduced the average pain score to $6.33 \pm 1.23(P<0.0001)$ when compared with the vehicle-treated group.

Administration of NYX-2925 Does Not Affect Acute Nociceptive Pain in the Rat Tail Flick Test. To investigate whether NYX-2925 administration produces analgesia in an acute nociceptive pain model, the rat tail flick test

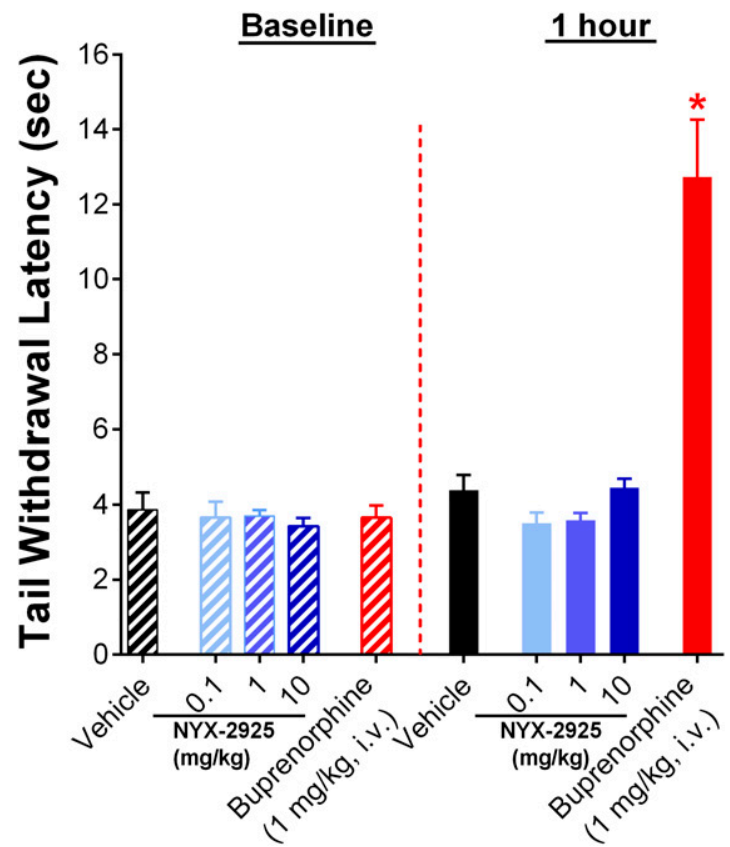

Fig. 5. NYX-2925 did not affect thermal nociception in the tail flick model of acute pain. Thermal analgesia was assessed by tail withdrawal latency from an infrared heat source. After baseline testing, animals were administered vehicle, NYX-2925 $(0.1,1$, or $10 \mathrm{mg} / \mathrm{kg})$, or buprenorphine $(1 \mathrm{mg} / \mathrm{kg}$, i.v.) and reassessed for thermal sensitivity 1 hour post drug administration. NYX-2925 was ineffective at all doses tested $(P>0.05)$. Buprenorphine significantly increased tail withdrawal latency 1 hour post dosing $(P<0.05) . N=7$ animals per group. Data represent means \pm S.E.M. *Statistically significant differences when compared with the vehicle group at the same time point $(P<0.05)$.

was performed. In this experiment, baseline tail withdrawal latencies (in seconds) from an infrared heat source were measured prior to dosing and then again at 1 hour post drug administration. As shown in Fig. 5, NYX-2925 did not affect thermal nociception at any of the doses tested $(0.1,1$, or $10 \mathrm{mg} / \mathrm{kg}$ ) when measured 1 hour after drug administration $[F(4,30)=0.2200, P=0.9252]$. The NYX-2925-treated rats had tail withdrawal latencies (following all three doses) that were similar to the vehicle-treated group and similar to the baseline values (Fig. 5). Rats treated with the positive control, buprenorphine $\mathrm{HCl}(1 \mathrm{mg} / \mathrm{kg}$, i.v. ), had significantly elevated thermal withdrawl latency when compared with the vehicle-treated group tested 1 hour after drug administration $(P<0.0001)$.

Direct mPFC Infusion of NYX-2925 Has a Significant and Long-Lasting Analgesic Effect in the Rat CCI Model of Neuropathic Pain. The $\mathrm{mPFC}$ is considered a central regulator of neuropathic pain (Apkarian et al., 2005; Cordeiro Matos et al., 2015). Direct mPFC administration of centrally acting compounds, such as D-cycloserine (an NMDAR glycine-site partial agonist), have been shown to reduce chronic pain (Millecamps et al., 2007). To assess the potential efficacy of NYX-2925 to reduce pain after direct mPFC infusion, bilateral guide cannulae were implanted immediately after the CCI surgery. NYX-2925 infused directly into the mPFC produced a significant and dose-dependent mechanical analgesia at the 20 -minute $[F(3,24)=16.18, P<0.0001], 24$-hour $[F(3,25)=$ $16.40, P<0.0001]$, and 1-week $[F(3,24)=9.228, P=0.0003]$ time points in the rat CCI model of neuropathic pain (Fig. 6A). 


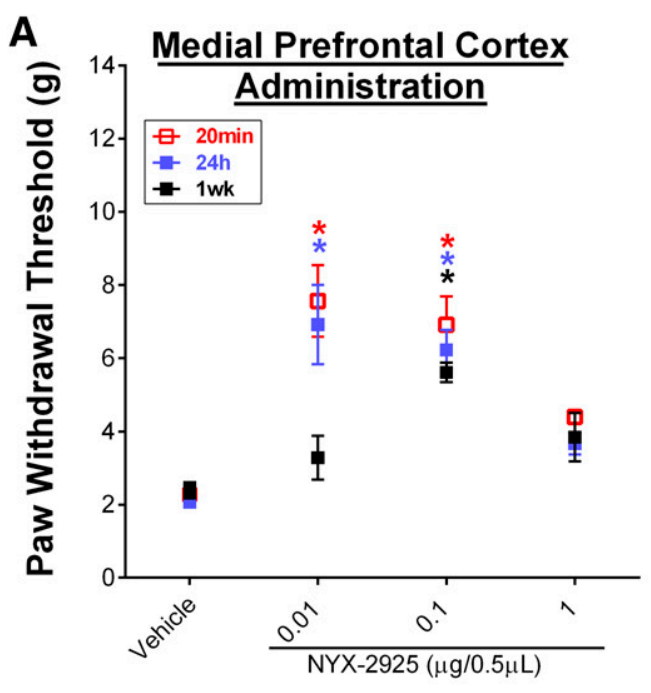

B

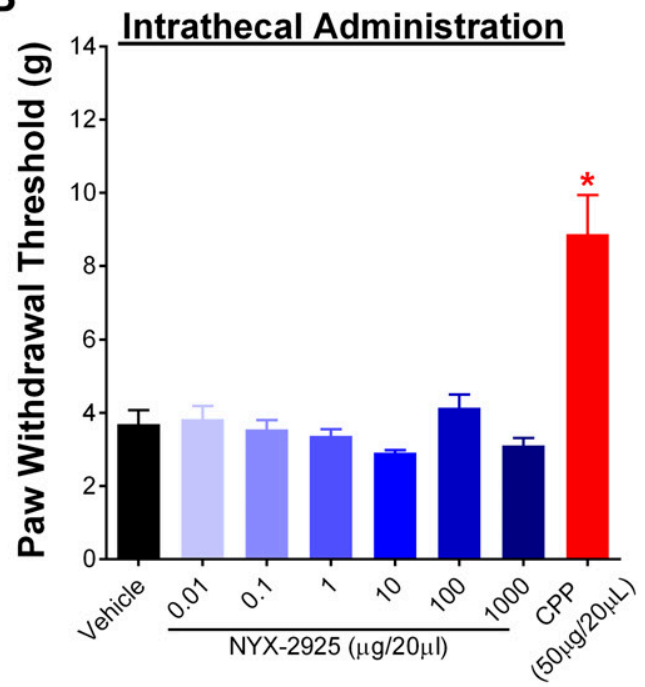

C

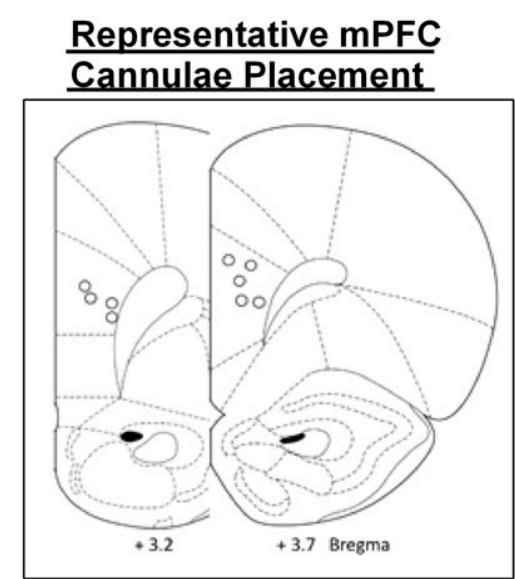

Fig. 6. Bilateral infusion of NYX-2925 into the medial prefrontal cortex produced significant and long-lasting mechanical analgesia in the CCI model of neuropathic pain. (A) After the onset of neuropathic pain, CCI animals were administered a bilateral $\mathrm{mPFC}$ infusion of vehicle or NYX$2925(0.01,0.1$, or $1 \mu \mathrm{g}$ into each guide cannulae) and assessed for analgesic effect, as measured by PWT at 20 minutes, 24 hours, or 1 week post drug administration. Administration of $0.01 \mu \mathrm{g}$ of NYX-2925 significantly increased PWT at 20 minutes and 24 hours post administration, but not at 1 week post administration versus vehicle $(P<0.05)$. Administration of $0.1 \mu \mathrm{g}$ significantly increased PWT at all time points
Twenty minutes following administration, NYX-2925 produced significant mechanical analgesia at 0.01 and $0.1 \mu \mathrm{g}$ $(P<0.0001$ for both concentrations). The analgesic effects of NYX-2925 at $0.01 \mu \mathrm{g}$ lasted up to 24 hours, but dissipated by 1 week. Infusion of $0.1 \mu \mathrm{g}$ of NYX-2925 was analgesic at all three time points tested. The highest concentration of NYX-2925 did not produce mechanical analgesia $(P>0.05)$ at any time point tested. After pain assessment, brains were collected, sectioned, and stained to verify correct cannulae placement in the $\mathrm{mPFC}$ (Fig. 6C).

Intrathecal Injection of NYX-2925 Does Not Produce Analgesia in the Rat CCI Model of Neuropathic Pain. NMDAR antagonists have been shown to induce analgesic activity in neuropathic pain models when administered directly onto the spinal cord (Näsström et al., 1992; Chaplan et al., 1997), whereas the NMDAR partial agonist DCS is ineffective after direct intrathecal delivery (Millecamps et al., 2007). Pharmacokinetic analysis to assess the amount of NYX-2925 reaching the spinal cord following oral administration was used to guide the dosage choice for intrathecal studies (Sai Life Sciences). Oral administration of NYX-2925 at $10 \mathrm{mg} / \mathrm{kg}$ resulted in a maximum of $233 \mathrm{nM}$ compound in the spinal cord at 1 hour (Fig. 7). Subsequently, a wide dose range around this concentration was used to assess analgesic efficacy in the intrathecal study (Fig. 6B). Since most sciatic afferents enter the spinal cord along the L4 and L5 dorsal roots, an injection of $20 \mu \mathrm{l}$ of NYX-2925 (0.01-1000 $\mu \mathrm{g})$, CPP (50 $\mu \mathrm{g})$, or vehicle was administered between the L4 and L5 vertebrae (Devor et al., 1985). Intrathecal administration of NYX-2925 did not produce significant mechanical analgesia compared with vehicle-treated CCI rats for any of the doses tested $(P>0.05)$ (Fig. 6B). Intrathecal administration of the NMDAR antagonist CPP (positive control) produced significant mechanical analgesia $[F(7,56)=14.56, P<0.0001]$.

Systemic Pretreatment of the NMDAR Antagonist CPP Inhibits the Analgesic Effect of NYX-2925 in the Rat CCI Model of Neuropathic Pain. To assess the reliance of NYX-2925 on functional NMDA receptors, the NMDAR antagonist CPP $(10 \mathrm{mg} / \mathrm{kg}$, i.p. $)$ was administered 1 hour prior to NYX-2925 (10 mg/kg, PO) to a group of CCI animals. Separate groups of animals were dosed with $1 \mathrm{ml} / \mathrm{kg}$ saline (i.p.) at the same time. One hour later, those groups were orally dosed with vehicle (0.5\% CMC), NYX-2925, CPP, or gabapentin $(150 \mathrm{mg} / \mathrm{kg}, \mathrm{PO})$. Mechanical analgesia was assessed using von Frey filaments at 1 and 24 hours after compound administration. As expected, a single dose of NYX-2925

versus vehicle $(P<0.05)$. The highest concentration of NYX-2925 $(1 \mu \mathrm{g})$ did not increase PWT at any of the time points tested $(P>0.05) . N=6-9$ animals per group. (B) NYX-2925 did not produce mechanical analgesia when delivered via intrathecal administration in the CCI model of neuropathic pain. Two to 3 weeks post CCI surgery, animals were administered intrathecal injections of saline vehicle, NYX-2925 (0.01-1000 $\mu \mathrm{g} / 20 \mu \mathrm{l}$ saline), or CPP $(50 \mu \mathrm{g} / 20 \mu \mathrm{l}$ saline $)$ and assessed for analgesic effect, as measured by PWT, 30-45 minutes post drug administration. NYX-2925 did not increase PWT at any concentration tested versus the vehicle control group $(P>0.05)$. CPP significantly increased PWT versus vehicle $(P<0.05)$. $N=5-12$ animals per group. Data represent means \pm S.E.M. *Statistically significant differences when compared with the vehicle group at the same time point $(P<0.05)$. (C) Medial PFC cannulae placements are shown. All microinjection sites were located within the prelimbic mPFC according to the atlas of Paxinos and Watson. 

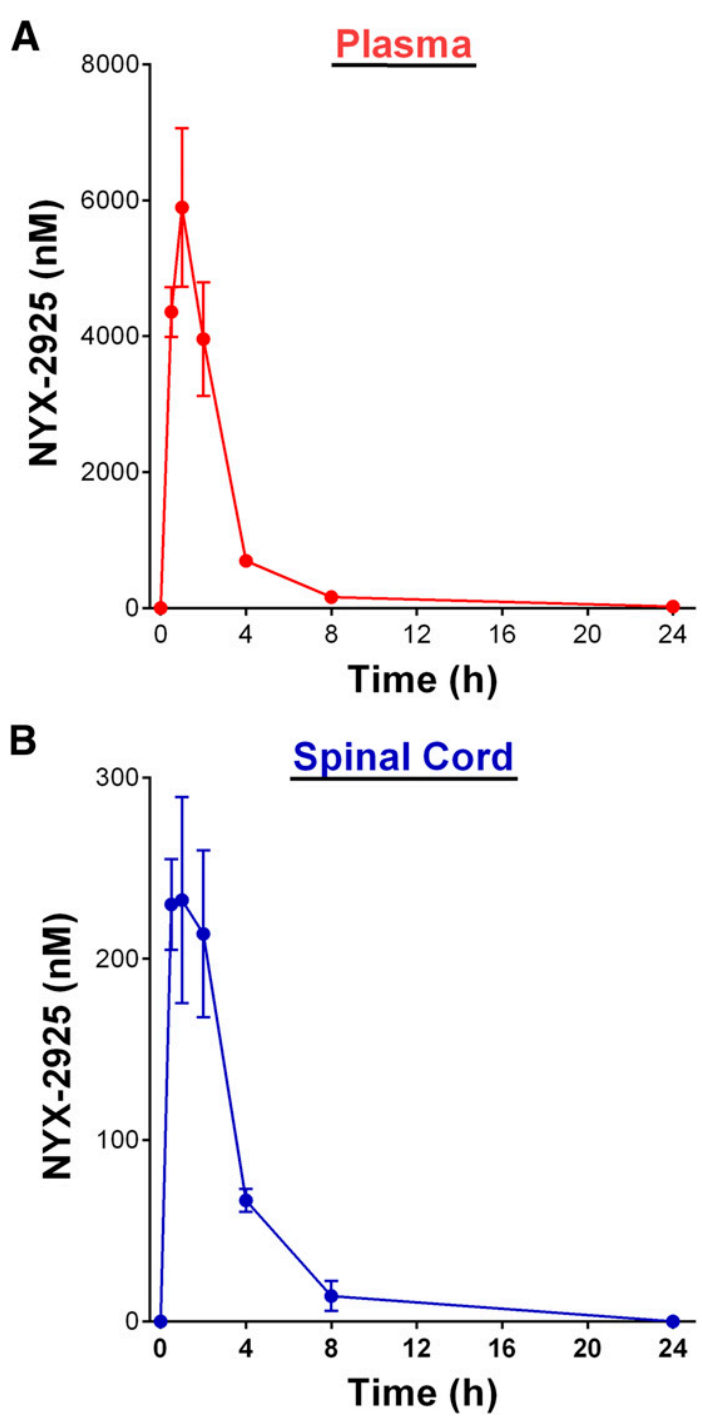

Fig. 7. Pharmacokinetic analysis of NYX-2925 in plasma and spinal cord. Overnight-fasted Sprague-Dawley rats were orally dosed with NYX-2925 at $10 \mathrm{mg} / \mathrm{kg}$ (in $0.9 \%$ saline). Plasma (A) and spinal cords (B) were collected at $0.5,1,2,4,8$, and 24 hours post administration. Samples were extracted, and pharmacokinetic analysis of the samples was performed using liquid chromatography-tandem mass spectrometry. $N=3$ rats/time point.

resulted in significant and long-lasting analgesia when compared with the vehicle group [1 hour: $F(4,24)=11.91, P<$ 0.0001 ; and 24 hours: $F(4,23)=9.046, P<0.001]$. Administration of CPP prior to NYX-2925 blocked the analgesic effects previously seen at both the 1- and 24-hour time points $(P>0.05)$. Systemic administration of CPP had no effect on its own when tested at both the 1- and 24-hour time points when compared with the vehicle-treated group (Fig. 8). Gabapentin, the positive control, produced significant but short-lasting analgesia only at the 1-hour time point $(P<0.01)$.

NYX-2925 Reverses the Decrease and the Increase in Aversive Ultrasonic Vocalizations Observed with CCI-Induced Neuropathic Pain in Rats. Neuropathic pain has been shown to impair learning and memory, increase negative affect, and induce anhedonia (Moriarty et al., 2011; Bushnell et al., 2013; Low, 2013). The heterospecific

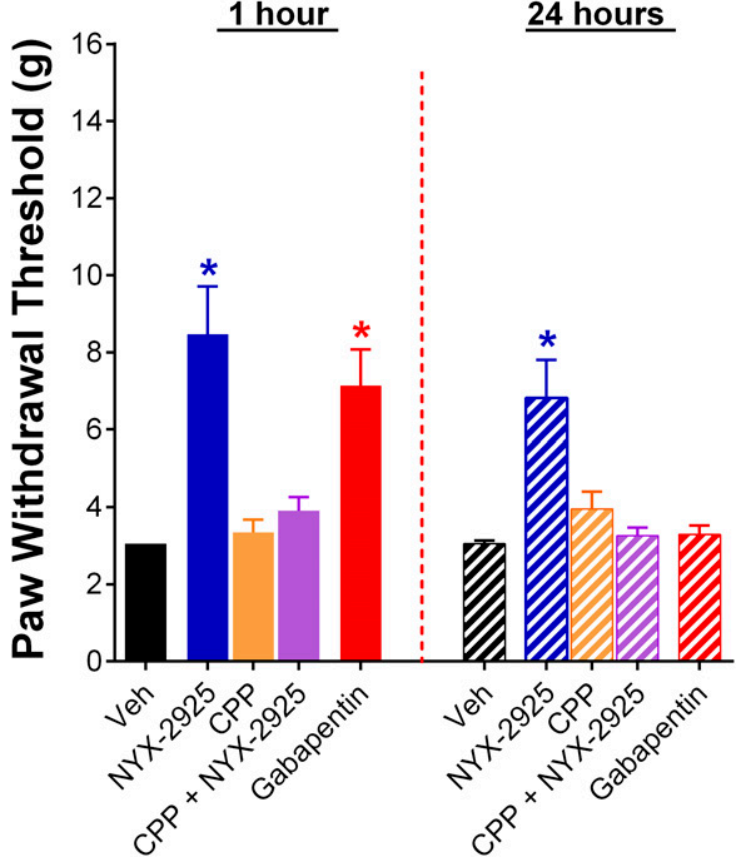

Fig. 8. Analgesic efficacy of NYX-2925 is blocked by systemic preadministration of CPP. To assess the reliance of NYX-2925 on functional NMDA receptors, the NMDAR antagonist CPP was administered 1 hour prior to NYX-2925 in a group of CCI animals. Other groups were dosed with saline 1 hour prior to the administration of vehicle (Veh), NYX-2925 (10 mg/kg, PO), CPP (10 mg/kg, i.p.), or gabapentin (150 mg/kg, PO). Animals were assessed for mechanical hypersensitivity at 1 and 24 hours post dose. NYX-2925 administration was analgesic at both time points $(P<0.05)$. Preadministration of CPP blocked the analgesic effect of NYX2925 at both time points tested $(P>0.05)$. Gabapentin effects were transient, and were observed only at the 1-hour time point. $N=6$ animals per group. Data represent means \pm S.E.M. *Statistically significant differences when compared with the vehicle group at the same time point $(P<0.05)$

rough-and-tumble-play assay is an NMDAR-dependent task that allows for the evaluation of affective state as well as positive emotional learning (Burgdorf et al., 2011a). Thus, this model was used to evaluate the effect of CCIinduced neuropathic pain on these parameters and the potential of NYX-2925 to reverse any observed deficits. Hedonic (frequency modulated $50-\mathrm{kHz}$ ) and aversive $(20-\mathrm{kHz})$ vocalizations were quantified during six roughand-tumble-play trials as previously described (Burgdorf et al., 2011a). Vocalizations occurring during the 15-second nonstimulation periods are considered to be a measure of positive emotional learning (Burgdorf et al., 2011a). In addition, the latency to approach the experimenter's hand was assessed to measure the rewarding value of heterospecific play. Vehicle-administered sham-surgery animals were used as a comparison with vehicle-administered CCIsurgery animals and NYX-2925-administered CCI animals to evaluate the effect of NYX-2925 on reversing any deficits seen in CCI animals.

Three weeks following CCI surgery, vehicle-treated CCI rats emitted fewer hedonic USVs during the nonstimulation period when compared to sham-surgery animals $[F(3,31)=$ 9.303, $P<0.0001$ ] (Fig. 9A). NYX-2925 (1 or $10 \mathrm{mg} / \mathrm{kg}, \mathrm{PO}$ ) administration increased hedonic USVs in trials (T) 2-6 [T2: $F$ $(3,31)=4.864, P<0.01$; T3: $F(3,31)=7.560, P<0.001 ; \mathrm{T} 4: F$ $(3,31)=5.748, P<0.01$; T5: $F(3,31)=7.322, P<0.001 ;$ and 


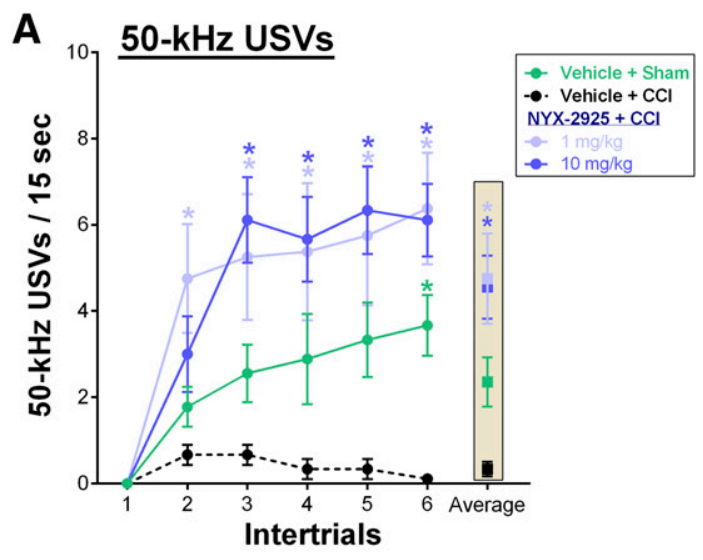

B
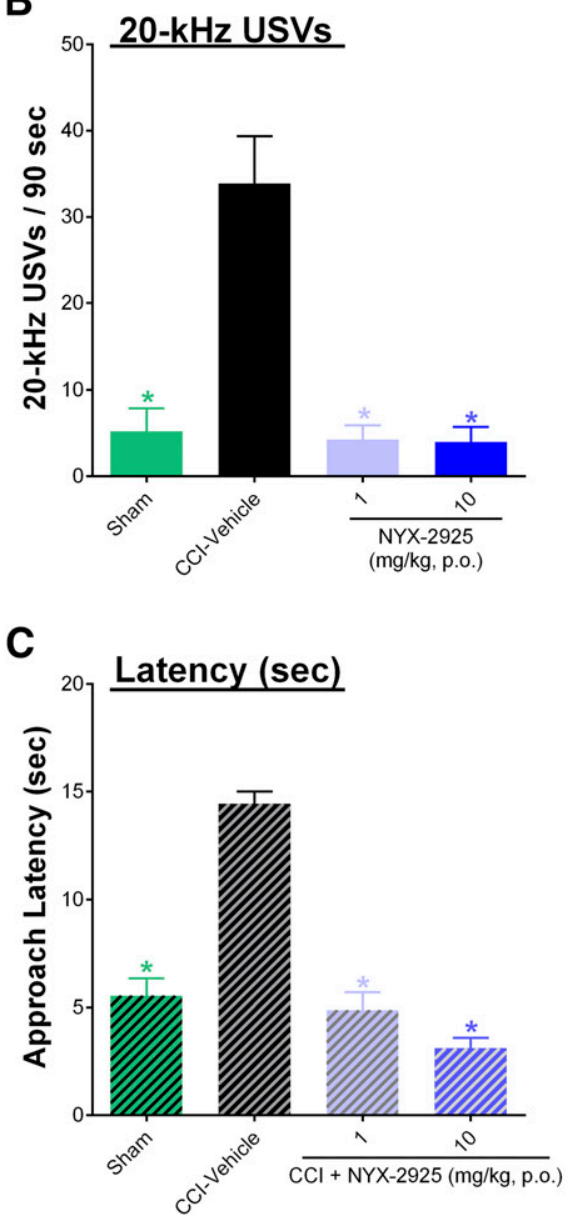

Fig. 9. In the heterospecific rough-and-tumble-play assay, NYX-2925 reversed deficits seen in hedonic and ultrasonic vocalizations caused by CCI-induced neuropathic pain. (A) CCI-induced neuropathic pain decreased $50-\mathrm{kHz}$ ultrasonic vocalizations during the 15 -second nonstimulation periods between trials when compared with sham-surgery animals $(P<0.05)$. A trend was seen in trials $1-5$, and a significant difference was observed in trial $6(P<0.05)$. A single administration of NYX-2925 to CCI rats, 1 hour prior to the first trial, significantly increased hedonic $50-\mathrm{kHz}$ ultrasonic vocalizations in trials $2-6$ and trials $3-6$ for 1 and $10 \mathrm{mg} / \mathrm{kg}$, respectively, when compared with the CCI-vehicle control $(P<0.05)$. (B) CCI-induced neuropathic pain significantly increased aversive $20-\mathrm{kHz}$ vocalizations across nonstimulation periods when compared with shamsurgery animals $(P<0.05)$. A single administration of NYX-2925 (1 or $10 \mathrm{mg} / \mathrm{kg}$ ) to the CCI rats significantly decreased $20-\mathrm{kHz}$ ultrasonic vocalizations $(P<0.05)$. (C) CCI-induced neuropathic pain significantly increased the latency to approach the experimenter's hand to selfadminister heterospecific play when compared with the sham-surgery animals $(P<0.05)$. A single administration of NYX-2925 $(1 \mathrm{or} 10 \mathrm{mg} / \mathrm{kg})$ to
T6: $F(3,31)=12.65, P<0.0001]$ in CCI rats measured 1 hour after administration when compared with the vehicle-treated group. Aversive (20-kHz) ultrasonic vocalizations, which were summed for all nonstimulation periods across trials, were increased in CCI rats compared with the sham-surgery group $[F(3,31)=19.73, P<0.0001] . \mathrm{NYX}-2925(1$ and $10 \mathrm{mg} / \mathrm{kg}, \mathrm{PO})$ administration significantly decreased $(P<0.0001)$ aversive USVs in CCI rats when compared with the vehicle-treated CCI group (Fig. 9B). CCI animals also showed significantly higher latency to approach the experimenter's hand to selfadminister heterospecific play when compared with the shamsurgery group $(P<0.05)$. NYX-2925 $(1$ and $10 \mathrm{mg} / \mathrm{kg}, \mathrm{PO})$ administration to the CCI rats significantly decreased $(P<$ $0.05)$ this latency when compared with the vehicle-treated CCI group $[F(3,31)=57.38, P<0.0001]$ (Fig. 9C).

\section{Discussion}

NYX-2925 markedly reduced pain and improved positive affect in preclinical neuropathic pain models. In the formalin test, NYX-2925 reduced spontaneous pain readouts after formalin injection. NYX-2925 also decreased thermal hyperalgesia and mechanical hypersensitivity in the CCI peripheral nerve injury model. Repeat administration of NYX-2925 resulted in dose-dependent and sustained analgesic effects in the CCI model. In the STZ-induced diabetic neuropathy model, NYX-2925 alleviated allodynia in a dose-dependent manner.

A single administration of NYX-2925 resulted in significant and long-lasting mechanical analgesia which, unlike gabapentin, persisted for at least 7 days in both the CCI and STZ models. This long-lasting analgesic activity extends beyond the availability of NYX-2925 in the brain, as the compound has a cerebral spinal fluid half-life of under 2 hours in rats (Khan et al., 2018). We postulate that the long-lasting analgesia may stem from NYX-2925-mediated synaptic plasticity. Ongoing work in our laboratory has demonstrated that NYX-2925 binds directly to NMDA receptors, causing conformational changes (Khan et al., 2018) that lead to rapid influx of calcium and enhancement of long-term potentiation measured in both the rat hippocampal and prefrontal cortex (Khan et al., 2018). Ex vivo studies have shown significantly enhanced long-term potential in the mPFC of rats treated with NYX-2925 taken 24 hours post treatment compared with the untreated controls (Khan et al., 2018). Moreover, dendritic spine analyses have shown a significant increase in both numbers of spines and "mature" spine morphologies (Khan et al., 2018). Thus, the long-lasting effects of NYX-2925 in neuropathic pain are likely mediated through these changes in structural plasticity.

The data presented here also show that the analgesic effects of NYX-2925 were NMDAR-dependent, as analgesia was blocked by the systemic administration of CPP. Moreover, analgesic effects were also achieved by direct administration of NYX-2925 into the mPFC. Thus, the analgesic effect of NYX-2925 appears to impact neuropathic pain via a central mechanism.

the CCI rats significantly decreased this latency when compared with vehicle-administered CCI animals $(P<0.05)$. $N=8-9$ animals per group. Data represent means \pm S.E.M. *Statistically significant differences when compared with the vehicle group at the same time point $(P<0.05)$. 
Brain imaging studies in patients and laboratory animals suggest an anatomic and functional shift in activated cortical and subcortical circuitry as pain becomes chronic (Apkarian et al., 2011, 2013; Hashmi et al., 2013). Specifically, chronic pain is associated with increased involvement of brain emotional and corticolimbic circuitry and decreased involvement of somatosensory circuitry (Baliki et al., 2006; Geha et al., 2007; Farmer et al., 2011; Parks et al., 2011). This is particularly apparent within the $\mathrm{mPFC}$, where the level of connectivity to regions including the insula and nucleus accumbens is highly correlated with pain intensity (Baliki et al., 2014). Accordingly, increased regional coincident activity can be used to predict the transition from acute to chronic pain (Apkarian et al., 2013) as well as to provide a potential indicator for the efficacy of pain therapeutics (Napadow et al., 2012).

NYX-2925 was not effective in the reflexive tail flick acute model of nociceptive pain. This supports the specific target of NYX-2925 function to be within corticolimbic circuitry since the tail flick response is a spinally mediated phenomenon. Further support for this comes from reports that other compounds with analgesic effects in neuropathic pain conditions do not show effects in the tail flick test (Smith et al., 2017), which further reinforces the concept that neuropathic pain is distinct from nociceptive pain.

The composition of spinal NMDARs (Boyce et al., 1999; Nagy et al., 2004; Wee et al., 2008) is similar to those found in the cortex (Wu and Zhuo, 2009), and these receptors are critically involved in inflammatory and neuropathic pain (Dickenson et al., 1997). For example, spinal excitatory neurons appear to be in a perpetually potentiated state, as if long-term potential is saturated in these neurons following peripheral neuropathic or inflammatory injury (Liu and Sandkuhler, 1997; Zhang et al., 2004; Ikeda et al., 2006). Thus, NMDAR antagonists (Kim and Jeong, 2013; Wang et al., 2017) such as ketamine show analgesic activity when administered directly into the spinal cord (Chaplan et al., 1997).

In contrast, the prelimbic $\mathrm{mPFC}$ is hypoactive in chronic pain, and neuropathic pain can be reversed by increasing mPFC activity with optogenetic tools (Lee et al., 2015; Wang et al., 2015; Zhang et al., 2015). Thus, despite the efficacy of intrathecal ketamine to reduce pain, no analgesia was observed after intracerebral administration (Chaplan et al., 1997). Correspondingly, neither the glycine site partial agonist DCS nor NYX-2925 was effective intrathecally, but analgesia was observed following direct administration of either compound into the mPFC (Fig. 6A) (Millecamps et al., 2007).

We suggest that the absence of intrathecal NYX-2925 efficacy stems from dorsal horn pain circuits being in a hyperactive state following peripheral neuropathic pain or inflammatory injury (Miraucourt et al., 2007; Price and Prescott, 2015). In contrast, because NYX-2925 increases NMDAR current and facilitates long-term potentiation in the mPFC (Khan et al., 2018), we hypothesize that NYX2925 alleviates pain by reversing the neuropathy-induced hypoactivity of the $\mathrm{mPFC}$.

Perhaps because the $\mathrm{mPFC}$ is hypoactive in chronic pain (Ji and Neugebauer, 2011; Kelly and Martina, 2018), these patients frequently experience deficits in affect, attention, memory, and decision making (Kodama et al., 2011; Moriarty et al., 2011; Bushnell et al., 2013; Ceko et al., 2015). Thus, the changes in the prelimbic PFC likely exacerbate pain and contribute to the increased emotionality of the pain state experienced by these patients. We believe that the affective component of pain can also be seen in rodents using heterospecific rough-and-tumble play. In rats, Frequency-modulated $50-\mathrm{kHz}$ and $20-\mathrm{kHz}$ USVs are validated measures of positive and negative emotion, respectively (Burgdorf et al., 2011b), and the expression of hedonic $50-\mathrm{kHz}$ USVs depends on the NMDAR-driven synaptic plasticity in the mPFC (Burgdorf et al., 2015a). A recent study in naïve rodents showed that NYX-2925 administration led to an NMDAR-dependent increase in hedonic vocalizations (Khan et al., 2018). Here, we investigated hedonic and aversive rat ultrasonic vocalizations as a measure of nonevoked/spontaneous pain using heterospecific rough-and-tumble play in CCI rats. NYX-2925 improved hedonic learning as evidenced by greater $50-\mathrm{kHz}$ hedonic calls during the nonstimulation periods, decreased hand-approach latencies, and decreased $20-\mathrm{kHz}$ aversive calls. These data suggest that NYX-2925 has the potential to reverse the occurrence of $\mathrm{mPFC}$-dependent emotional and learning deficits that are highly comorbid with chronic pain.

In summary, corticolimbic NMDA receptor modulation, as exemplified by NYX-2925, is a novel approach for the treatment of neuropathic pain. NYX-2925 is also unique relative to current pain therapeutics in that it can induce rapid and longlasting analgesic effects in a variety of neuropathic pain models while also improving emotional and cognitive deficits associated with chronic pain.

\section{Acknowledgments}

We thank Dr. Roger Kroes, Dr. Torsten Madsen, Dr. Crystle Kelly, and Dr. Marina Asiedu for helpful discussions.

\section{Authorship Contributions}

Participated in research design: Moskal, Cearley, Burgdorf, Ghoreishi-Haack.

Conducted experiments: Ghoreishi-Haack, Priebe, Colechio, Aguado, Burgdorf.

Contributed new reagents or analytic tools: Khan.

Performed data analysis: Ghoreishi-Haack, Burgdorf.

Wrote or contributed to the writing of the manuscript: GhoreishiHaack, Cearley, Burgdorf, Bowers, Moskal.

\section{References}

Abbott FV, Franklin KB, and Westbrook RF (1995) The formalin test: scoring properties of the first and second phases of the pain response in rats. Pain 60:91-102. Apkarian AV, Baliki MN, and Farmer MA (2013) Predicting transition to chronic pain. Curr Opin Neurol 26:360-367.

Apkarian AV, Bushnell MC, Treede RD, and Zubieta JK (2005) Human brain mechanisms of pain perception and regulation in health and disease. Eur J Pain $\mathbf{9}$ : 463-484.

Apkarian AV, Hashmi JA, and Baliki MN (2011) Pain and the brain: specificity and plasticity of the brain in clinical chronic pain. Pain 152(3 Suppl):S49-S64.

Backonja M, Arndt G, Gombar KA, Check B, and Zimmermann M (1994) Response of chronic neuropathic pain syndromes to ketamine: a preliminary study. Pain 56: 51-57.

Baliki MN, Chialvo DR, Geha PY, Levy RM, Harden RN, Parrish TB, and Apkarian AV (2006) Chronic pain and the emotional brain: specific brain activity associated with spontaneous fluctuations of intensity of chronic back pain. $J$ Neurosci $\mathbf{2 6}$ : 12165-12173.

Baliki MN, Mansour AR, Baria AT, and Apkarian AV (2014) Functional reorganization of the default mode network across chronic pain conditions. PLoS One 9:e106133.

Barker GR and Warburton EC (2008) NMDA receptor plasticity in the perirhinal and prefrontal cortices is crucial for the acquisition of long-term object-in-place associative memory. J Neurosci 28:2837-2844.

Bennett GJ and Xie YK (1988) A peripheral mononeuropathy in rat that produces disorders of pain sensation like those seen in man. Pain 33:87-107.

Boyce S, Wyatt A, Webb JK, O'Donnell R, Mason G, Rigby M, Sirinathsinghji D, Hill RG, and Rupniak NM (1999) Selective NMDA NR2B antagonists induce antinociception without motor dysfunction: correlation with restricted localisation of NR2B subunit in dorsal horn. Neuropharmacology 38:611-623. 
Burgdorf J, Knutson B, Panksepp J, and Ikemoto S (2001) Nucleus accumbens amphetamine microinjections unconditionally elicit $50-\mathrm{kHz}$ ultrasonic vocalizations in rats. Behav Neurosci 115:940-944.

Burgdorf J, Kroes RA, Weiss C, Oh MM, Disterhoft JF, Brudzynski SM, Panksepp J, and Moskal JR (2011a) Positive emotional learning is regulated in the medial prefrontal cortex by GluN2B-containing NMDA receptors. Neuroscience 192:515-523.

Burgdorf J, Kroes RA, Zhang XL, Gross AL, Schmidt M, Weiss C, Disterhoft JF, Burch RM, Stanton PK, and Moskal JR (2015a) Rapastinel (GLYX-13) has therapeutic potential for the treatment of post-traumatic stress disorder: characterization of a NMDA receptor-mediated metaplasticity process in the medial prefrontal cortex of rats. Behav Brain Res 294:177-185.

Burgdorf J and Panksepp J (2001) Tickling induces reward in adolescent rats. Physiol Behav 72:167-173.

Burgdorf J, Panksepp J, and Moskal JR (2011b) Frequency-modulated 50 kHz ultrasonic vocalizations: a tool for uncovering the molecular substrates of positive affect. Neurosci Biobehav Rev 35:1831-1836.

Burgdorf J, Zhang XL, Nicholson KL, Balster RL, Leander JD, Stanton PK, Gross AL, Kroes RA, and Moskal JR (2013) GLYX-13, a NMDA receptor glycine-site functional partial agonist, induces antidepressant-like effects without ketaminelike side effects. Neuropsychopharmacology 38:729-742.

Burgdorf J, Zhang XL, Weiss C, Gross A, Boikess SR, Kroes RA, Khan MA, Burch RM, Rex CS, Disterhoft JF, et al. (2015b) The long-lasting antidepressant effects of rapastinel (GLYX-13) are associated with a metaplasticity process in the medial prefrontal cortex and hippocampus. Neuroscience 308:202-211.

Bushnell MC, Ceko M, and Low LA (2013) Cognitive and emotional control of pain and its disruption in chronic pain. Nat Rev Neurosci 14:502-511.

Ceko M, Gracely JL, Fitzcharles MA, Seminowicz DA, Schweinhardt P, and Bushnell MC (2015) Is a responsive default mode network required for successful working memory task performance? $J$ Neurosci 35:11595-11605.

Chaplan SR, Bach FW, Pogrel JW, Chung JM, and Yaksh TL (1994) Quantitative assessment of tactile allodynia in the rat paw. J Neurosci Methods 53:55-63.

Chaplan SR, Malmberg AB, and Yaksh TL (1997) Efficacy of spinal NMDA receptor antagonism in formalin hyperalgesia and nerve injury evoked allodynia in the rat. J Pharmacol Exp Ther 280:829-838.

Coderre TJ and Melzack R (1992) The contribution of excitatory amino acids to central sensitization and persistent nociception after formalin-induced tissue injury. J Neurosci 12:3665-3670.

Cordeiro Matos S, Zhang Z, and Séguéla P (2015) Peripheral neuropathy induces $\mathrm{HCN}$ channel dysfunction in pyramidal neurons of the medial prefrontal cortex. $J$ Neurosci 35:13244-13256.

Cull-Candy S, Brickley S, and Farrant M (2001) NMDA receptor subunits: diversity, development and disease. Curr Opin Neurobiol 11:327-335.

D'Amour FE and Smith DL (1941) A method for determining loss of pain sensation. $J$ Pharmacol Exp Ther 72:74-79.

Devor M, Govrin-Lippmann R, Frank I, and Raber P (1985) Proliferation of primary sensory neurons in adult rat dorsal root ganglion and the kinetics of retrograde cell loss after sciatic nerve section. Somatosens Res 3:139-167.

De Vry J, Kuhl E, Franken-Kunkel P, and Eckel G (2004) Pharmacological characterization of the chronic constriction injury model of neuropathic pain. Eur $J$ Pharmacol 491:137-148.

Dickenson AH, Chapman V, and Green GM (1997) The pharmacology of excitatory and inhibitory amino acid-mediated events in the transmission and modulation of pain in the spinal cord. Gen Pharmacol 28:633-638.

Dubuisson D and Dennis SG (1977) The formalin test: a quantitative study of the analgesic effects of morphine, meperidine, and brain stem stimulation in rats and cats. Pain 4:161-174.

Ellis A, Benson N, Machin I, and Corradini L (2008) The rat formalin test-can it predict neuropathic pain treatments? in Proceedings of Measuring Behavior; 2008 August 26-29; Maastricht, The Netherlands.

Farmer MA, Chanda ML, Parks EL, Baliki MN, Apkarian AV, and Schaeffer AJ (2011) Brain functional and anatomical changes in chronic prostatitis/chronic pelvic pain syndrome. $J$ Urol 186:117-124

Finnerup NB, Attal N, Haroutounian S, McNicol E, Baron R, Dworkin RH, Gilron I, Haanpää M, Hansson P, Jensen TS, et al. (2015) Pharmacotherapy for neuropathic pain in adults: a systematic review and meta-analysis. Lancet Neurol 14:162-173.

Geha PY, Baliki MN, Chialvo DR, Harden RN, Paice JA, and Apkarian AV (2007) Brain activity for spontaneous pain of postherpetic neuralgia and its modulation by lidocaine patch therapy. Pain 128:88-100.

Gilron I, Baron R, and Jensen T (2015) Neuropathic pain: principles of diagnosis and treatment. Mayo Clin Proc 90:532-545.

Gilron I and Dickenson AH (2014) Emerging drugs for neuropathic pain. Expert Opin Emerg Drugs 19:329-341.

Hargreaves K, Dubner R, Brown F, Flores C, and Joris J (1988) A new and sensitive method for measuring thermal nociception in cutaneous hyperalgesia. Pain 32:77-88.

Hashmi JA, Baliki MN, Huang L, Baria AT, Torbey S, Hermann KM, Schnitzer TJ, and Apkarian AV (2013) Shape shifting pain: chronification of back pain shifts brain representation from nociceptive to emotional circuits. Brain 136:2751-2768.

Häuser W, Bock F, Engeser P, Tölle T, Willweber-Strumpfe A, and Petzke F (2014) Long-term opioid use in non-cancer pain. Dtsch Arztebl Int 111:732-740.

Holla S, Amberkar MB, Bhandarypanambur R, Kamalkishore M, and Janardhanan M (2015) Cycloserine induced late onset psychosis and ethambutol induced peripheral neuropathy associated with MDR-TB treatment in an Indian patient- a rare case report. $J$ Clin Diagn Res 9:FD01-FD03.

Hsieh GC, Honore P, Pai M, Wensink EJ, Chandran P, Salyers AK, Wetter JM, Zhao C, Liu H, Decker MW, et al. (2010) Antinociceptive effects of histamine H3 receptor antagonist in the preclinical models of pain in rats and the involvement of central noradrenergic systems. Brain Res 1354:74-84.

Ikeda H, Stark J, Fischer H, Wagner M, Drdla R, Jäger T, and Sandkühler J (2006) Synaptic amplifier of inflammatory pain in the spinal dorsal horn. Science $\mathbf{3 1 2}$ $1659-1662$
Ji G and Neugebauer V (2011) Pain-related deactivation of medial prefrontal cortical neurons involves mGluR1 and GABA(A) receptors. $J$ Neurophysiol 106:2642-2652.

Kelly CJ and Martina M (2018) Circuit-selective properties of glutamatergic inputs to the rat prelimbic cortex and their alterations in neuropathic pain. Brain Struct Funct 223:2627-2639.

Khan GM, Chen SR, and Pan HL (2002) Role of primary afferent nerves in allodynia caused by diabetic neuropathy in rats. Neuroscience 114:291-299.

Khan MA, Houck DR, Gross AL, Zhang XL, Cearley C, Madsen TM, Kroes RA, Stanton PK, Burgdorf J, and Moskal JR (2018) NYX-2925 is a novel NMDA receptor-specific spirocyclic- $\beta$-lactam that modulates synaptic plasticity processes associated with learning and memory. Int $J$ Neuropsychopharmacol 21:242-254.

Kim MA and Jeong KY (2013) Chronological changes of mechanical allodynia and spinal microglia activation by an intrathecal injection of MK-801. Neuroreport 24: $585-589$

Kodama D, Ono H, and Tanabe M (2011) Increased hippocampal glycine uptake and cognitive dysfunction after peripheral nerve injury. Pain 152:809-817.

Lee M, Manders TR, Eberle SE, Su C, D'amour J, Yang R, Lin HY, Deisseroth K, Froemke RC, and Wang $J$ (2015) Activation of corticostriatal circuitry relieves chronic neuropathic pain. J Neurosci 35:5247-5259.

Liu X and Sandkühler J (1997) Characterization of long-term potentiation of C-fiberevoked potentials in spinal dorsal horn of adult rat: essential role of NK1 and NK2 receptors. J Neurophysiol 78:1973-1982.

Low LA (2013) The impact of pain upon cognition: what have rodent studies told us? Pain 154:2603-2605.

Mak P, Broadbear JH, Kolosov A, and Goodchild CS (2015) Long-term antihyperalgesic and opioid-sparing effects of 5-day ketamine and morphine infusion ("burst ketamine") in diabetic neuropathic rats. Pain Med 16:1781-1793.

Malcangio M and Tomlinson DR (1998) A pharmacologic analysis of mechanical hyperalgesia in streptozotocin/diabetic rats. Pain 76:151-157.

Mestre C, Pélissier T, Fialip J, Wilcox G, and Eschalier A (1994) A method to perform direct transcutaneous intrathecal injection in rats. J Pharmacol Toxicol Methods 32:197-200.

Millan MJ and Seguin L (1994) Chemically-diverse ligands at the glycine B site coupled to N-methyl-D-aspartate (NMDA) receptors selectively block the late phase of formalin-induced pain in mice. Neurosci Lett 178:139-143.

Millecamps M, Centeno MV, Berra HH, Rudick CN, Lavarello S, Tkatch T, and Apkarian AV (2007) D-cycloserine reduces neuropathic pain behavior through limbic NMDA-mediated circuitry. Pain 132:108-123.

Mills C, Leblond D, Joshi S, Zhu C, Hsieh G, Jacobson P, Meyer M, and Decker M (2012) Estimating efficacy and drug ED50's using von Frey thresholds: impact of weber's law and log transformation. J Pain 13:519-523.

Miraucourt LS, Dallel R, and Voisin DL (2007) Glycine inhibitory dysfunction turns touch into pain through PKCgamma interneurons. PLoS One 2:e1116.

Moriarty O, McGuire BE, and Finn DP (2011) The effect of pain on cognitive function: a review of clinical and preclinical research. Prog Neurobiol 93:385-404.

Morrow TJ (2004) Animal models of painful diabetic neuropathy: the STZ rat model. Curr Protoc Neurosci Chapter 9:Unit 9.18.

Nagy GG, Watanabe M, Fukaya M, and Todd AJ (2004) Synaptic distribution of the NR1, NR2A and NR2B subunits of the N-methyl-d-aspartate receptor in the rat lumbar spinal cord revealed with an antigen-unmasking technique. Eur J Neurosci 20:3301-3312

Napadow V, Kim J, Clauw DJ, and Harris RE (2012) Decreased intrinsic brain connectivity is associated with reduced clinical pain in fibromyalgia. Arthritis Rheum 64:2398-2403.

Näsström J, Karlsson U, and Post C (1992) Antinociceptive actions of different classes of excitatory amino acid receptor antagonists in mice. Eur $J$ Pharmacol 212:21-29.

Newton VL, Guck JD, Cotter MA, Cameron NE, and Gardiner NJ (2017) Neutrophils infiltrate the spinal cord parenchyma of rats with experimental diabetic neuropathy. J Diabetes Res 2017:4729284.

Niesters M, Martini C, and Dahan A (2014) Ketamine for chronic pain: risks and benefits. Br J Clin Pharmacol 77:357-367.

Parks EL, Geha PY, Baliki MN, Katz J, Schnitzer TJ, and Apkarian AV (2011) Brain activity for chronic knee osteoarthritis: dissociating evoked pain from spontaneous pain. Eur J Pain 15:843.e1-843.e14.

Paxinos G and Watson C (1998) The Rat Brain in Stereotaxic Coordinates, 4th ed, Academic Press, New York

Price TJ and Prescott SA (2015) Inhibitory regulation of the pain gate and how its failure causes pathological pain. Pain 156:789-792.

Schnitzer TJ, Torbey S, Herrmann K, Kaushal G, Yeasted R, and Vania Apkarian A (2016) A randomized placebo-controlled pilot study of the efficacy and safety of D-cycloserine in people with chronic back pain. Mol Pain 12.

Seguin L and Millan MJ (1994) The glycine B receptor partial agonist, (+)-HA966 enhances induction of antinociception by RP 67580 and CP-99,994. Eur J Pharmacol 253:R1-R3.

Singh L, Field MJ, Ferris P, Hunter JC, Oles RJ, Williams RG, and Woodruff GN (1996) The antiepileptic agent gabapentin (Neurontin) possesses anxiolytic-like and antinociceptive actions that are reversed by D-serine. Psychopharmacology (Berl) 127:1-9.

Smith MD, Woodhead JH, Handy LJ, Pruess TH, Vanegas F, Grussendorf E, Grussendorf J, White K, Bulaj KK, Krumin RK, et al. (2017) Preclinical comparison of mechanistically different antiseizure, antinociceptive, and/or antidepressant drugs in a battery of rodent models of nociceptive and neuropathic pain. Neurochem Res 42:1995-2010.

Traynelis SF, Wollmuth LP, McBain CJ, Menniti FS, Vance KM, Ogden KK, Hansen KB, Yuan H, Myers SJ, and Dingledine R (2010) Glutamate receptor ion channels: structure, regulation, and function. Pharmacol Rev 62:405-496.

Wang GQ, Cen C, Li C, Cao S, Wang N, Zhou Z, Liu XM, Xu Y, Tian NX, Zhang Y, et al. (2015) Deactivation of excitatory neurons in the prelimbic cortex via Cdk5 promotes pain sensation and anxiety. Nat Commun 6:7660. 
Wang J, Qiao Y, Yang RS, Zhang CK, Wu HH, Lin JJ, Zhang T, Chen T, Li YQ, Dong YL, et al. (2017) The synergistic effect of treatment with triptolide and MK-801 in the rat neuropathic pain model. Mol Pain 13: 1744806917746564

Wee KS, Zhang Y, Khanna S, and Low CM (2008) Immunolocalization of NMDA receptor subunit NR3B in selected structures in the rat forebrain, cerebellum, and lumbar spinal cord. J Comp Neurol 509:118-135.

Wood PL, Mahmood SA, and Moskal JR (2008) Antinociceptive action of GLYX-13: an $\mathrm{N}$-methyl-D-aspartate receptor glycine site partial agonist. Neuroreport 19: $1059-1061$.

Wu LJ and Zhuo M (2009) Targeting the NMDA receptor subunit NR2B for the treatment of neuropathic pain. Neurotherapeutics 6:693-702.
Zhang HM, Zhou LJ, Hu XD, Hu NW, Zhang T, and Liu XG (2004) Acute nerve injury induces long-term potentiation of C-fiber evoked field potentials in spinal dorsal horn of intact rat. Sheng Li Xue Bao 56:591-596.

Zhang Z, Gadotti VM, Chen L, Souza IA, Stemkowski PL, and Zamponi GW (2015) Role of prelimbic GABAergic circuits in sensory and emotional aspects of neuropathic pain. Cell Rep 12:752-759.

Address correspondence to: Nayereh Ghoreishi-Haack, Aptinyx, Inc., Suite 4300, 1801 Maple Avenue, Evanston, IL 60201. E-mail: nayerehhaack@ aptinyx.com 